\title{
CLINICAL USES OF 2,3-DIMERCAPTOPROPANOL (BAL). VI. THE TREATMENT OF COMPLICATIONS OF ARSENO-THERAPY WITH BAL (BRITISH ANTI-LEWISITE) ${ }^{1}$
}

\author{
By A. B. CARleton, R. A. PETERS, L. A. STOCKEN, R. H. S. THOMPSON, ANd \\ D. I. WILLIAMS WITH APPENDIX UPON EXCRETION OF ARSENIC \\ BY I. D. E. STOREY, G. A. LEVVY, AND A. C. CHANCE \\ (From the Departments of Dermatology and Biochemistry, Oxford, the Royal Victoria \\ Hospital, Westbury, and the Departments of Medical Chemistry and \\ Pharmacology, Edinburgh)
}

(Received for publication February 5, 1946)

\section{INTRODUCTION}

This report presents the clinical evidence available in Great Britian up to September, 1944, upon the therapeutic effect of British Anti-Lewisite or BAL (also called OX 217 for security reasons during the war) in cases of arsenical dermatitis. There is some indication that this compound has a curative action; but as often happens in clinical trials, the evidence collected is not yet sufficient to present a definite case, even after a year's work, owing to the scarcity of available material. Nevertheless, it is certain that the compound merits further trial. A brief summary will be given of the biochemical background and of the clearcut experiments on which promise of clinical success is based, as well as a discussion of what can be expected clinically from an arsenical antidote.

In recent years, as the results of research in many laboratories, progress in our knowledge of the intermediary metabolism of carbohydrates has led to more detailed information on the progressive steps by which the carbohydrates, glucose and glycogen, are broken down in cells to carbon dioxide and water; a recent review of this work is given by Meyerhof (1). Each step is controlled by a definite enzyme, and many involve phosphorylations. One of the penultimate stages of this degradation is pyruvic acid, a three carbon keto-acid. In so far as tissue cells rely upon carbohydrates for their energy, the stages in breakdown are all of importance. It follows that one way of interfering with cell life is to interrupt the activity of some enzyme essential to tissue carbo-

1 This paper is published, with minor changes, from the original report prepared at the request of the U. K. Army authorities for the British Medical Research Council. hydrate metabolism. For instance, it is known that when thiamine (aneurin) is deficient in brain tissue, the brain cells concerned are sufficiently disturbed to produce a convulsive state in the animal: here aneurin is a component of the organized group of enzymes (or 'enzyme system') responsible for the oxidation of pyruvic acid, which is usually called the pyruvate oxidase system. This system has protein and other components; hence interruption of tissue metabolism can occur at this stage not only by deficiency of the vitamin, but also by active interference with the functioning of any of these components by poisons. This work has been reviewed by Peters (2) who has generalized such changes as 'biochemical lesion.'

Some years ago it was realised by Peters (3) that the poisons, iodoacitic acid and dichlordiethyl sulphone, which can induce pathological change in skin, have a selective inhibitory action on the pyruvate oxidase enzyme system. It was further known before the war that arsenite too interferes with the metabolism of pyruvic acid (4) and that the pyruvate oxidase system contains a component sensitive to very small concentrations of arsenite, which also act selectively on it at these levels $(5,6)$. It follows that the metabolism of carbohydrate is poisoned at an important stage by traces of an arsenical. This is the predominant way in which arsenicals can cause biochemical lesions, and any antidote must be capable of reversing this biochemical damage.

On the basis of these facts, it is logical to use the pyruvate oxidase system as well as the more classical method of in vivo injection as a test for new antidotes against arsenic, and during the war a research upon these lines was initiated and 
pursued by a team in Oxford (7). As a result of the systematic attack made on this problem from the biochemical angle, it was found $(8,9)$ that simple 1,2-dithiols (of which $\mathrm{BAL}, \mathrm{CH}_{2} \mathrm{SH} \cdot \mathrm{CH}$ $\mathrm{SH} \cdot \mathrm{CH}_{2} \mathrm{OH}$, is an example) are capable both of exerting a marked antidotal action against the poisoning of this enzyme system by trivalent arsenicals, and, more important still, of reversing this poisoning when once established. These effects are brought about through the ability of 1,2-dithiols to form stable ring compounds with trivalent arsenicals,

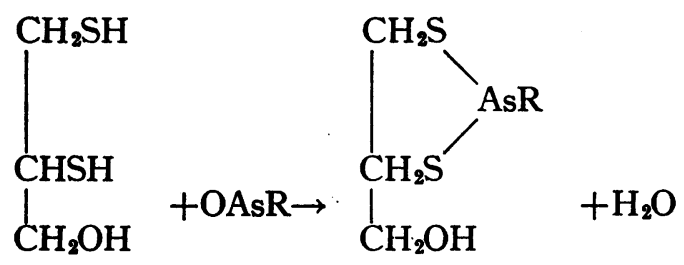

instead of the much more dissociable "open chain" compounds formed between arsenic and the monothiols investigated in the past.

It was at once clear that in addition to experiments with Lewisite, extended in vivo trials with the therapeutic arsenicals were needed. These were undertaken and it was clearly shown that the administration of BAL is highly effective in bringing about the survival of rats after the injection of lethal amounts of Mapharside (M-amino-phyrdoxyphenylarsenoxide hydrochloride), even when the drug is not administered until after the injection of a lethal dose of the arsenical. The results of some experiments reported elsewhere (10) given in Table I will illustrate this:

Mapharside, freshly dissolved in glass-distilled $\mathrm{H}_{2} \mathrm{O}$, was injected intramuscularly into the hindlegs of rats weighing from about 150 to 200 grams each. At intervals varying from 5 to 15 minutes after injecting the arsenical, BAL, dissolved in propylene glycol, was injected intramuscularly in doses of 40 to $50 \mathrm{mgm}$. per $\mathrm{kgm}$. into the opposite hind leg.

It should be pointed out that although the interval between injection of the arsenical and treatment with BAL is short, the toxic effects produced by doses of Mapharside of this order come on with great rapidity: after 15 minutes the rats already show marked signs of generalized intoxication (salivation, lachrymation and diarrhea), many being in a state of collapse. Similar results
TABLE I

Effect of injected $B A L$ on the survival of rats after administration of lethal doses of Mapharside

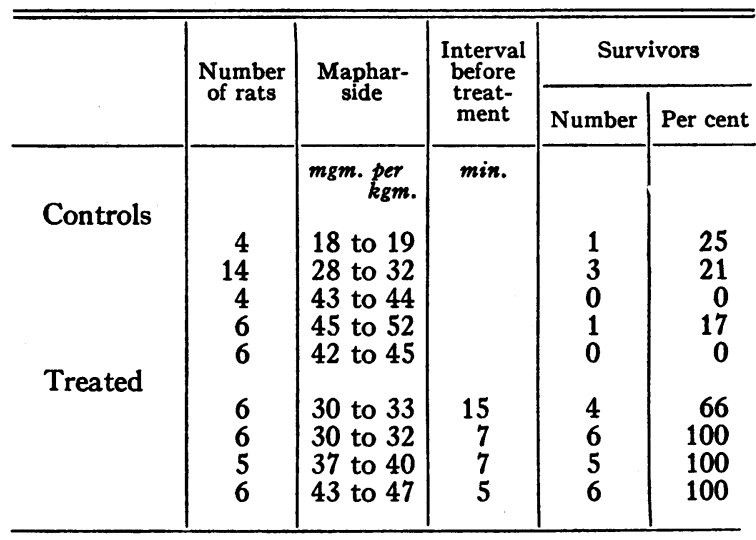

while this work was in progress were reported from America by Eagle (11).

Biochemical evidence has therefore been obtained which shows that BAL is capable not only of combining with free, circulating arsenic, but also of displacing it once it has reacted with tissue components. In view of this, it was expected that BAL therapy might lead to an increased renal excretion of arsenic. This point has been studied in animals suffering from poisoning by trivalent arsenicals, and it was clearly shown by Thompson and Stocken (12) that under the conditions of these experiments, treatment with BAL brings about a significant and rapid increase in the amount of arsenic excreted in the urine. More recently results from Edinburgh strikingly confirm this (13).

The experimental work outlined above was so definite that it justified a study of the efficiency of this compound in the treatment of toxic manifestations of the therapeutic arsenicals in man. For the initial assessment, it seemed desirable to investigate severe cases showing signs of sufficient intensity to reveal any specific therapeutic action, and it was therefore decided to begin with a study of BAL therapy in cases of acute exfoliative arsenical dermatitis.

\section{METHOD OF ADMINISTRATION}

In view of the fact that BAL had not previously been administered internally to man, it was decided to commence with inunction of a 5 per cent ointment.

Applied by this route and in this concentration, it was known from earlier work in Oxford and in the U. S. A. that the compound is rapidly absorbed, and that the oint- 
ment can be applied over large areas of normal skin without giving rise to any severe systemic toxic effects. Locally the application of BAL to the skin does bring about transient erythema and tingling, and in some persons, an edematous, urticarial reaction, which subsides, however, in about 2 to 3 hours. Repeated application of BAL to the same area of skin is to be avoided on account of the possibility of a low-grade skin sensitization to the compound, as demonstrated by Sulzberger and Baer (14). It seemed likely that application to an already inflamed skin should also be avoided, so that in the treatment of cases of dermatitis the inunction was made into normal skin, or, in cases where the skin involvement was general, into an area of skin showing minimal involvement. In all except the earliest of the cases treated by inunction, applications of approximately $1 \mathrm{gram}$ of the ointment were rubbed in over a small area of skin, and when repeated on successive days, different areas were chosen each day.

The BAL was made up on a 5 per cent $W / V$ basis in the following vehicle:

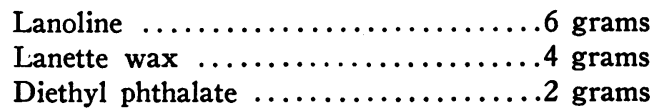

It was soon realized that although some success was attending this method of administration, the route was far from satisfactory, and it was decided to turn to injection.

At the time when we were considering, as a first step, the injection of aqueous solutions of BAL, known to be effective in animals (15), our attention was drawn (priviate communication) to Eagle's demonstration $(16,11)$ that 5 per cent BAL in 10 per cent benzyl benzoate in peanut oil, given by intramuscular injection, is an effective therapeutic agent in animals, and that this solution was also suitable for administration to man. As there was some urgency in arriving at a suitable method of administration, we decided at once to try Eagle's formula. An improved method of ampoule preparation (17) ensured that less than 1.5 per cent of BAL was destroyed during the sterilization, as compared to 10 per cent by Eagle's original method. When adapted for large-scale production, the final ampoules contained a 5 per cent $\mathrm{W} / \mathrm{V}$ solution of BAL in 10 per cent $\mathrm{W} / \mathrm{V}$ benzyl benzoate in peanut oil, being nitrogen-filled and sterilized by heating for 1 hour at $170^{\circ} \mathrm{C}$.

The total dosage given varied from case to case according to the condition of the patient, but usually consisted of a course of $2 \mathrm{ml}$. given by deep intramuscular injection into the gluteal region twice daily for 3 or 4 days, followed by a further course, if no obvious improvement occurred, or if, at any time, there were signs of any relapse in the condition of the skin.

In the great majority of cases the injections have been well tolerated, but in a few, local abscesses developed at the injection sites. This point will be discussed later in greater detail, but the impression gained was that the abscess formation was as much due to the general septic condition of the patient, arising from the heavy secondary infection of the skin not infrequently present, as to the BAL itself.

\section{Considerations upon skin conditions due to ar- senicals.}

Certain changes may be expected in the skin of patients developing an arsenical dermatitis.

(a) Very small amounts of arsenic will be enough to cause biochemical lesions, or even death, of the tissue cells. For instance, it can be calculated that an area of skin $30 \mathrm{~cm}$. square, might be poisoned by as little as $0.02 \mathrm{mgm}$. arsenic. Even if, therefore, an antidote removes arsenic by combination with it and excretion of the resulting product, the increase in the variable daily excretion of arsenic in the urine might be too small to be readily detected.

(b) Cells subjected to the action of arsenic for some time may be able to live feebly by relying upon other channels of metabolism, and will not immediately recover completely when the combined arsenic is removed. Hence a pathological state may remain as long as the slow rebuilding of cell enzymes takes place. If there is, in addition, much loss of plasma protein by weeping, and of skin by exfoliation, this will be a cause for additional delay in healing ; there will, in effect, exist a condition analogous to that of a thermal burn.

(c) It is almost certain that tissue stores of arsenical compounds must exist in quantities such that, even when arsenic has been removed from the skin, the weakened cells may be repoisoned, occasioning relapses. This condition would be more likely to occur in cases subjected to long periods of arsenical treatment.

(d) Toxic manifestations are not necessarily due to the actual presence of arsenic, but may result from sensitization to a foreign protein brought into being by the arsenic. In these cases, there may be no arsenic in the skin, so that the dermatitis would not be affected by an arsenical antidote.

Reflection upon these 4 points indicates that in all probability, some cases of so-called arsenical dermatitis cannot respond to an antidote, and, further, that in those cases that do respond the signs due to the immediate presence of the arsenic will disappear, but will leave a slowly healing residuum. The clinical proof is further handicapped by the additional complication of skin in- 
fection. We should expect the most direct prooofs of therapeutic value in acute cases resulting from intensive therapy with Mapharside, since they will have the highest body content of arsenic at the time of dosing.

\section{RESULTS}

The 30 cases described in this article may be grouped into:

(a) 18 cases treated by injection.

(b) 9 cases treated by inunction.

(c) 3 cases whose interpretation, for reasons described later, is uncertain.

Detailed clinical notes of the cases, together with a summary, are given in Appendix I, and the results of arsenic estimations in the urine and skin in Appendix II.

In order to simplify the interpretation of the progress observed, all other local treatment was, whenever possible, discouraged, and to no case after coming under our notice were preparations of sodium thiosulphate given. Where circumstances permitted, the skin was photographed before starting treatment with BAL, and again as soon as any obvious improvement had taken place.

\section{(a) Cases treated by injection.}

The 18 cases in this series were all severe or moderately severe, showing weeping or desquama- tion or exfoliation from the affected areas. Two of the cases ended fatally: Case No. 6 died suddenly after mild rigors, and at autopsy showed a terminal broncho-pneumonia, while Case No. 15 developed a sloughing glossitis, stomatitis and pharyngitis and an early granulocytopenia.

The duration, in days, of the skin disturbance in the remaining 16 cases is given in Table II. It will be seen that the mean duration is $\mathbf{3 8 . 9}$ days, with a range of from 5 to 90 days. In 6 of the cases, the patient was not followed through until the skin was reported as normal; Table II, therefore, also gives the dates when the skin was reported as 'almost normal,' i.e., normal except for some slight and localised disturbance, the nature and extent of which can be seen by reference to the case report.

Of the 18 cases treated by injection the number of days from the first injection of BAL to the time when the skin became 'normal' or 'almost normal' is also given, the mean times being 27.6 days for those followed through to 'normal' and 18.9 days for those in which an 'almost normal' report was received.

It will be seen from Table II that 3 of these injection cases (Nos. 8, 11 and 18) showed no dramatic response to the drug as regards the time taken for complete, or nearly complete, heal-

TABLE II

Duration of dermatitis in patients treated by injection

\begin{tabular}{|c|c|c|c|c|c|c|c|}
\hline \multirow{2}{*}{$\begin{array}{c}\text { Case } \\
\text { number }\end{array}$} & \multirow{2}{*}{ Date of onset } & \multirow{2}{*}{$\begin{array}{l}\text { Date of first in- } \\
\text { jection of BAL }\end{array}$} & \multirow{2}{*}{$\begin{array}{l}\text { Date when 'almost } \\
\text { normal' }\end{array}$} & \multirow{2}{*}{ Date when normal } & \multirow{2}{*}{$\begin{array}{l}\text { Total dura- } \\
\text { tion of der- } \\
\text { matitis }\end{array}$} & \multicolumn{2}{|c|}{$\begin{array}{l}\text { Number of days from first } \\
\text { injection to time when }\end{array}$} \\
\hline & & & & & & Normal & $\begin{array}{l}\text { 'Almost } \\
\text { normal' }\end{array}$ \\
\hline \multirow{4}{*}{$\begin{array}{r}1 \\
2 \\
3 \\
4 \\
5 \\
6 \\
7 \\
8 \\
9 \\
10 \\
11 \\
12 \\
13 \\
14 \\
15 \\
16 \\
17 \\
18\end{array}$} & \multirow{4}{*}{$\begin{array}{c}10.10 .43 \\
7.10 .43 \\
21.11 .43 \\
2.12 .43 \\
22.12 .43 \\
\text { Died } \\
23.12 .43 \\
31.12 .43 \\
2.2 .44 \\
3.2 .44 \\
26.1 .44 \\
24.2 .44 \\
18.2 .44 \\
18.2 .44 \\
\text { Died } \\
24.2 .44 \\
\text { Dates not given } \\
\text { 20. } 4.44\end{array}$} & \multirow{4}{*}{$\begin{array}{r}3.11 .43 \\
12.11 .43 \\
5.12 .43 \\
8.12 .43 \\
26.12 .43 \\
9 . \\
\text { 9. } 1.44 \\
26.1 .44 \\
5 . \\
14.44 \\
14.2 .44 \\
16 . \\
\text { 18. } 2.44 \\
29.44 \\
\text { 6. } 3.44 \\
\text { 6. } 3.44 \\
\text { 29. } 4.44\end{array}$} & \multirow{4}{*}{$\begin{array}{r}3.12 .43 \\
3.12 .43 \\
\\
\text { 5. } 1.44 \\
\text { 18. } 1.44 \\
\text { 2. } 3.44 \\
\text { 12. } 2.44 \\
\text { 28. } 2.44 \\
6 \text { 6. 3.44 } \\
\text { 22. } 4.44 \\
14 . ~ 3.44 \\
\\
\text { 9. } 3.44 \\
\text { 13. } 6.44\end{array}$} & $\begin{array}{r}7.12 .43 \\
14.12 .43 \\
14.12 .43 \\
14.1 .44\end{array}$ & $\begin{array}{l}\text { days } \\
54 \\
61 \\
23 \\
12 \\
23\end{array}$ & $\begin{array}{r}25 \\
9 \\
6 \\
19\end{array}$ & $\begin{array}{l}30 \\
21 \\
\\
10\end{array}$ \\
\hline & & & & $\begin{array}{r}\text { 11. } 3.44 \\
\text { 4. } 3.44 \\
\text { 25. } 4.44 \\
\text { 23. } 3.44\end{array}$ & $\begin{array}{l}26 \\
72 \\
31 \\
25 \\
90 \\
58 \\
34\end{array}$ & $\begin{array}{l}45 \\
28 \\
69 \\
23\end{array}$ & $\begin{array}{r}9 \\
36 \\
7 \\
14 \\
19 \\
35 \\
14\end{array}$ \\
\hline & & & & 30. 3.44 & $\begin{array}{r}41 \\
14 \\
5 \\
54\end{array}$ & 24 & $\begin{array}{r}3 \\
3 \\
45\end{array}$ \\
\hline & & & & Mean $=$ & 38.9 & 27.6 & 18.9 \\
\hline
\end{tabular}


ing of the skin, Cases No. 8 and 11 taking 45 and 69 days respectively to return to normal, and Case No. 18, 45 days to return to 'almost normal.'

As pointed out earlier in this report, however, it is unlikely that the skin in all cases of arsenical dermatitis will heal rapidly following treatment with an arsenical antidote unless other measures are also taken to combat the loss of protein that is probably occurring simultaneously, owing to weeping or desquamation. It is of interest therefore to inspect the case reports in order to discover whether any partial healing, such as cessation of oozing or exfoliation, regularly took place after the injection of BAL, even though some residual skin changes, such as a persisting erythema, might remain.

In Table III are given the reports of such progress in the various cases at the stated number of

TABLE III

Progress of cases in response to $B A L$ injection

\begin{tabular}{|c|c|c|}
\hline $\begin{array}{c}\text { Case } \\
\text { number }\end{array}$ & Reported Progress & $\begin{array}{l}\text { Number } \\
\text { of days } \\
\text { after first } \\
\text { injection }\end{array}$ \\
\hline 1 & $\begin{array}{l}\text { All weeping ceased except for very slight } \\
\text { patches at upper end of sternum and on } \\
\text { buttocks }\end{array}$ & 6 \\
\hline $2^{*}$ & $\begin{array}{l}\text { Definite improvement. } \\
\text { Natural elasticity of skin almost regained. }\end{array}$ & $\begin{array}{l}2 \\
6\end{array}$ \\
\hline $\begin{array}{l}3 \\
4\end{array}$ & $\begin{array}{l}\text { Skin normal. } \\
\text { Rash disappeared. Residual pigmenta- } \\
\text { tion present. }\end{array}$ & $\begin{array}{l}9 \\
6\end{array}$ \\
\hline $\begin{array}{l}5 \\
6 \\
7\end{array}$ & $\begin{array}{l}\text { Skin normal except for soles of feet. } \\
\text { Died. } \\
\text { Skin clear of all scaling and erythema ex- } \\
\text { cept for scalp and feet. (Result com- } \\
\text { plicated by report of improvement } 2 \\
\text { days prior to injection.) }\end{array}$ & 10 \\
\hline 8 & $\begin{array}{l}\text { All skin areas dry. Still some desquama- } \\
\text { tion on neck, abdomen and forearms. }\end{array}$ & 16 \\
\hline 9 & $\begin{array}{l}\text { Skin normal except for slight erythema of } \\
\text { chest and desquamation of palms and } \\
\text { soles. }\end{array}$ & 7 \\
\hline 10 & $\begin{array}{l}\text { Marked improvement. No edema. Skin } \\
\text { dry and returning to normal color. } \\
\text { Scattered scaling, particularly on scalp. }\end{array}$ & 14 \\
\hline 11 & $\begin{array}{l}\text { General improvement. Still some dry des- } \\
\text { quamation with generalized erythema. }\end{array}$ & 19 \\
\hline 12 & $\begin{array}{l}\text { Condition satisfactory. Skin improving } \\
\text { steadily. }\end{array}$ & 12 \\
\hline 13 & $\begin{array}{l}\text { General condition much improved. Skin } \\
\text { dry and erythema subsiding. }\end{array}$ & 10 \\
\hline 14 & $\begin{array}{l}\text { Marked improvement. Hands and feet } \\
\text { stopped weeping. }\end{array}$ & 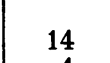 \\
\hline 15 & $\begin{array}{l}\text { Much less edema. } \\
\text { Relapse. Died. }\end{array}$ & $A$ \\
\hline $\begin{array}{l}16 \\
17 \\
18\end{array}$ & $\begin{array}{l}\text { Skin practically normal. } \\
\text { Skin practically normal. } \\
\text { Skin slowly returning to normal. }\end{array}$ & $\begin{array}{r}3 \\
3 \\
45\end{array}$ \\
\hline
\end{tabular}

* Local applications of BAL ointment given one month previously. days after the first injection of BAL. It will be seen that in all except the last case (No. 18), improvement, and in many instances marked improvement or a complete return to normal, took place in under 3 weeks from the first injection.

It must be pointed out that in only 4 of these cases was the dermatitis uncomplicated at any stage by other lesions, usually infective in type. Table IV briefly summarizes both the local com-

TABLE IV

Complications present in cases treated by injection

\begin{tabular}{|c|c|c|}
\hline $\begin{array}{c}\text { Case } \\
\text { number }\end{array}$ & Skin & General \\
\hline $\begin{array}{l}4 \\
5\end{array}$ & $\begin{array}{l}\text { Secondary infection of } \\
\text { toes and scalp. }\end{array}$ & $\begin{array}{l}\text { Purulent conjunctivitis } \\
\text { upper respiratory in- } \\
\text { fection. } \\
\text { Jaundice. } \\
\text { Abscess Rt. and Lt. glu- } \\
\text { teal region. } \\
\text { Terminal bronchopneu- } \\
\text { monia. }\end{array}$ \\
\hline 7 & $\begin{array}{l}\text { Generalized secondary } \\
\text { infection of skin. }\end{array}$ & $\begin{array}{l}\text { Conjunctivitis. Bleph- } \\
\text { aritis. Multiple styes } \\
\text { and boils. }\end{array}$ \\
\hline 8 & $\begin{array}{l}\text { Severe staphylococcal } \\
\text { infection. }\end{array}$ & $\begin{array}{l}\text { Axillary and inguinal } \\
\text { adenitis. }\end{array}$ \\
\hline $\begin{array}{r}9 \\
10\end{array}$ & Secondary infection of & Jaundice. \\
\hline 12 & $=e_{1}$ & $\begin{array}{l}\text { Abscess Rt. and Lt. but- } \\
\text { tock. } \\
\text { Infected throat. Ab- } \\
\text { scesses in axillae and } \\
\text { pubic region. }\end{array}$ \\
\hline 13 & $\begin{array}{l}\text { Infected patches on } \\
\text { each cheek. }\end{array}$ & Abscess Lt. buttock \\
\hline 14 & $\begin{array}{l}\text { Generalized secondary } \\
\text { infection. }\end{array}$ & \\
\hline 15 & & $\begin{array}{l}\text { Purulent conjunctivitis. } \\
\text { Sore throat. Early } \\
\text { granulocytopenia. }\end{array}$ \\
\hline $\begin{array}{l}16 \\
18\end{array}$ & Lat & $\begin{array}{l}\text { Slight conjunctivitis and } \\
\text { ulcerative stomatitis. }\end{array}$ \\
\hline
\end{tabular}

plications occurring in the skin, such as secondary pyogenic infection, and any other complications occurring either generally or in other organs.

Table V shows the incidence of local reactions to the injections in all cases, i.e., in the 18 cases of the series and in the 3 anomalous cases discussed later. It will be noted that in 4 patients, gluteal abscesses developed at the injection sites, while in a fifth, slight heat, tenderness and stiffness of the buttock appeared in 6 hours, but disappeared completely in 24 hours. In the remaining 16 cases, no local reaction was reported, though a few of the patients experienced a generalized irritation 
TAB LE V

Incidence of local reactions to injection of $B A L$

\begin{tabular}{|c|c|}
\hline $\begin{array}{c}\text { Case } \\
\text { number }\end{array}$ & Local reaction \\
\hline 4 & $\begin{array}{l}\text { Slight heat, tenderness and stiffness of the buttock, } \\
\text { appearing in } 6 \text { hours, and disappearing in } 24 \\
\text { hours. }\end{array}$ \\
\hline $\begin{array}{r}5 \\
11 \\
13 \\
28\end{array}$ & $\begin{array}{l}\text { Bilateral gluteal abscesses. } \\
\text { Bilateral gluteal abscesses. } \\
\text { Abscess Lt. buttock. } \\
\text { Two abscesses at injection sites. }\end{array}$ \\
\hline
\end{tabular}

No reaction in 13 of the 21 cases.

of the skin without visible signs following the injections.

\section{(b) Cases treated by inunction.}

Of these, the earliest cases studied, 4 out of 9 (Nos. 19, 20, 26 and 27) were comparatively mild, and never progressed to the stages of weeping or widespread desquamation, thus making it difficult to decide whether the progress observed was a true consequence of the BAL inunctions.

\section{(c) Remaining cases.}

Three further cases (Nos. 28, 29 and 30) are included, although the interpretation of therapeutic effects in them was very uncertain. In Case No. 28 it was impossible, owing to the existing war conditions, to obtain sufficient evidence of the patient's progress, particularly in the earlier stages; the patient received only 1 course of injections, and it is not clear from the records at our disposal whether a second course might not have been of use. In Case No. 29, although a marked improvement was noticed in the condition of the skin 2 days after the first injection, the patient relapsed one week later and was not given any further treatment. In Case No. 30 the eruption, though generalized, was so slight as to render difficult the interpretation of the rapid improvement observed.

\section{DISCUSSION}

The earliest reported work which is known to us on the treatment of arsenical dermatitis with BAL is that of Longcope, Wintrobe and Luetscher (18). They treated 6 patients, suffering from phenarsazine chloride dermatitis, by inunction of the affected areas with a 5 per cent BAL ointment. The results were described as good; the ointment was also effective when applied to the normal skin. Somewhat later the same authors stated that such treatment was followed by an increased excretion of arsenic in the urine. This account makes mention of 2 other patients treated by inunction, 1 had agranulocytosis and the other generalised exfoliative dermatitis, due to injected mapharsen and neoarsphenamine. Later, Eagle (16) reported a series of cases of arsenical dermatitis treated with injections of BAL; he suggested that there was evidence of a beneficial effect both upon the dermatitis and upon jaundice, when present. Our experience of treatment of post-arsphenamine jaundice with BAL was not favourable. In a series of cases treated at Netley by inunction there was no evidence that the jaundice was improved; in fact, most cases of so-called post-arsphenamine jaundice do not appear to be due to the continued presence of signficant quantities of arsenic in the liver (19).

The majority of cases discussed in this report had been treated with neoarsphenamine. The excessive reaction to small doses of the arsenical suggests that some of these cases are associated with some degree of arsenic sensitisation; Case No. 5 is a good exmaple of this. As will be seen in Table II, some cases showed a much quicker cure than others.

Although more patients are needed to get an adequate assessment of the clinical value of BAL, we shall attempt a summary of the position. The success of the new therapy must be judged by the acceleration in the rate of cure as compared with similar cases not treated with BAL. We have had the greatest difficulty in arriving at the average duration of severe cases of arsenical dermatitis treated by methods other than BAL. From notes made by one of us (D. I. W.) at Netley, we have a mean time of cure for 5 severe cases of 55 days (28 to 102). Two other cases of which we have received notes from Major Bolton lasted for 60 and 118 days. Davies (20) records the average duration of cure for 135 cases at his hospital from 1929 to 1941 , who had been dosed with neoarsphenamine, as 62.5 days, calculated from weighted mean figures. Mannix (private communication) considers 46 days an average time for cure for cases of varying severity. It is a well established clinical impression that patients showing exfoliation and oozing may take more than 2 months to 
cure. If we accept these estimates as the best available at present, it will be seen that the mean duration of 38.9 days (Table II) for our cases treated with $\mathrm{BAL}$ is a definite improvement. By a rough clinical assessment of each case, the conclusion was reached that 1 in 2 cases had been markedly improved by the treatment. Case No. 2 seems especially pertinent, because only a temporary improvement was made by inunction, whereas about 1 month later, injection caused a dramatic response. This does not present such a striking picture as that claimed in the early U. S. reports $(21,11,16)$; but from the clinical data in these reports it is difficult to discover the time for complete recovery in several cases, making comparison with our assessment difficult.

There seems to be a definite tendency in more than 1 case for a rapid cessation of the oozing, followed by a more intractable persistence of the erythema. This happened for instance in Case No. 1, where the erythema could not be reduced by inunction of an erythematous patch with BAL. This is consistent with the idea that capillary damage may be associated especially with the continued presence of arsenic, but that when this is removed, some damage to blood vessels remains and causes a slowly fading erythema. The low blood protein values suggest that general measures should be taken to combat loss due to exfoliative conditions ; a condition of protein deficiency alone would be sufficient to delay healing.

The assumption has been made throughout this report that the curative agent in the ampoules is BAL itself; on experimental grounds this assumption is justified. Nevertheless, we had planned to study, as a control, the effect of ampoules containing only peanut oil and benzyl benzoate; the opportunity for this has not yet arisen.

Reference to Appendix II shows that there was no experimental evidence of increase in arsenical excretion as a result of injecting BAL. In our opinion, close examination of the data in Eagle's report does not bear out his contention that arsenical excretion was increased. We are therefore forced to conclude that no such effect has been clearly demonstrated in cases of this type. At the same time, we think that this result is not surprising. It is known that damage by an arsenical is induced with very small amounts of the poison, and that the metabolically active layers of epidermis are not deep. The arsenic content of the urine is low; since, therefore, the arsenic responsible for continued damage in the skin is probably no more than a few micrograms, this would be masked by the general day-to-day fluctuation in arsenic excretion. In our patients, many of the figures approach normal levels. Bang (22) recorded values of 0.01 to $0.06 \mathrm{mgm}$. arsenic per $\mathrm{L}$. as usual values in the urine of normal individuals, though occasional excretions of $0.2,0.4$ and even 0.69 were noticed; these marked daily excretions in the same individuals probably depend upon the arsenic content of the diets. Webster (23) found average values of $0.015 \mathrm{mgm}$. per $\mathrm{L}$. for a group of normal individuals, and rather higher values, $0.050 \mathrm{mgm}$. per L., for those who had ingested fruit sprayed with lead arsenate. The late Professor A. J. Clark considered values for arsenic in urine in $\mathrm{mgm}$. per day as follows : $0.1 \mathrm{mgm}$. or less physiological ; 0.1 to $1.0 \mathrm{mgm}$., doubtful ; and $1.0 \mathrm{mgm}$. or more, direct poisoning. Our cases mostly fall in the doubtful class.

In confirmation of the results upon our patients, Chance (13) reported that injection of BAL did not increase urinary arsenic excretion in a rabbit with low total arsenic in the urine following dosage with Mapharside. It was quite otherwise when they had recently injected an arsenical, and there is some evidence by Black \& Trinder (private communication), to be published later, which suggests that BAL does increase excretion of arsenic in patients recently dosed with an arsenical drug.

Several cases also showed evidence of relapse. This can be explained if 'arsenic' from some other part of the body enters the blood stream and again poisons the skin. From our experience, good results have followed a second course of injection of BAL.

We have also had the opportunity of treating 2 cases of agranulocytopenia, and 1 of encephelopathy through the kindness of Lt. Col. Gordon and Major Blaisdell, R.C.A.M.C., and the Medical Officers concerned; three cases of agranulocytosis have been treated with BAL under the direction of Lt. Col. Pillsbury, U.S.A. Medical Corps. Although recovery has taken place in each of these cases, it is clear that we can conclude nothing final until more cases have been studied. It will be noted also that the excretion of arsenic was not much increased in Col. Gordon's 2 cases. 
It is realized that the number of cases available for this report is too small to eliminate the possibility of serious statistical error in the interpretation of the results. On the other hand, the striking clinical effect in some of the cases, and the apparent reduction in the time of healing, warrants a more extended trial of this new compound. The experimental evidence obtained from animals further supports this contention.

\section{SUMMARY}

1. Experimental evidence has shown that BAL will reverse the toxic action of Mapharside in animals.

2. BAL has been administered to 30 patients suffering from arsenical dermatitis, mostly following injections of neoarsphenamine; 21 of these cases were treated by intramuscular injection; and the remainder, by inunction. The clinical evidence indicated a beneficial effect in a substantial number of cases.

3. Estimation of arsenic excreted in the urine of several patients did not reveal any significant change due to treatment by BAL. The interpretation of this is discussed.

Case No. 1. Male, aged 30. Radcliffe Infirmary, Oxford.

Date

Professor L. Findlay.

14.7.43 to 15.9.43. N.A.B. 4.15 grams. Bis. 2.1 grams.

22.7.43. Pot. iodid. mixture.

15.10.43. Seen with rash on trunks and limbs, saying it had started 5 to 7 days previously. Skin itchy.

20.10.43. Admitted to hospital. Thiostab. 0.6 gram intravenously b.d. for 5 days, and then on alternate days.

30.10.43. Transferred to Radcliffe Infirmary, Oxford.

APPENDIX I

The treatment of complications of arseno-therapy with British Anti-Lewisite containing Summaries and Case Histories SUMMARY OF INJECTION CASES

\begin{tabular}{|c|c|c|c|c|}
\hline $\begin{array}{c}\text { Case } \\
\text { number }\end{array}$ & Condition at commencement of treatment & \begin{tabular}{|} 
Total num- \\
ber of days* \\
on which \\
BAL was \\
injected
\end{tabular} & Final report on condition of case & $\begin{array}{l}\text { Number } \\
\text { of days } \\
\text { from first } \\
\text { injection } \\
\text { of BAL }\end{array}$ \\
\hline 1 & $\begin{array}{l}\text { Severe generalized dermatitis with much crusting } \\
\text { and scaling. }\end{array}$ & 11 & $\begin{array}{l}\text { Skin condition practically normal, ex- } \\
\text { cept for slight erythema over inner } \\
\text { side of lower thighs. }\end{array}$ & 30 \\
\hline $2 * *$ & $\begin{array}{l}\text { Severe generalized dermatitis. Large areas on } \\
\text { trunk and legs moist and desquamating. }\end{array}$ & 6 & Skin normal. & 25 \\
\hline 3 & $\begin{array}{l}\text { Generalized erythroderma. Fine desquamation } \\
\text { on face. Dry, branny rash on trunk and arms. } \\
\text { Coarser exfoliation on legs. }\end{array}$ & 2 & Skin normal. & 9 \\
\hline 4 & $\begin{array}{l}\text { Generalized rather coarse eruption, characterized } \\
\text { by irregularly-shaped pink splashes, dry and } \\
\text { rough, and fine papules or small flat irregular } \\
\text { plaques with whitish surface. }\end{array}$ & 3 & $\begin{array}{l}\text { Rash disappeared. Residual pig- } \\
\text { mentation present. }\end{array}$ & 6 \\
\hline 5 & Generalized exfoliative dermatitis. & 3 & Skin normal. & 19 \\
\hline 6 & Severe generalized exfoliative dermatitis. & 3 & Died. & \\
\hline 7 & $\begin{array}{l}\text { Generalized moderately severe exfoliative derma- } \\
\text { titis. }\end{array}$ & 3 & $\begin{array}{l}\text { Skin clear of all scaling and erythema } \\
\text { except for scalp and feet. }\end{array}$ & 9 \\
\hline 8 & $\begin{array}{l}\text { Generalized exfoliative dermatitis affecting the } \\
\text { whole body except the soles of the feet. Oozing } \\
\text { of scalp and inner side of forearms, thighs and } \\
\text { legs. Exfoliating elsewhere. }\end{array}$ & 12 & Skin normal. & 45 \\
\hline 9 & $\begin{array}{l}\text { Generalized dusky erythroderma of whole body, } \\
\text { with fine desquamation, tending to be coarser on } \\
\text { the face. Erythema on chest. }\end{array}$ & 6 & Skin normal. & 28 \\
\hline 10 & $\begin{array}{l}\text { Generalized dermatitis with desquamation and } \\
\text { weeping. }\end{array}$ & 3 & $\begin{array}{l}\text { Skin dry and returning to normal } \\
\text { color. Scattered scaling, particu- } \\
\text { larly on scalp. }\end{array}$ & 14 \\
\hline
\end{tabular}


APPENDIX I-Continued

\begin{tabular}{|c|c|c|c|c|}
\hline $\begin{array}{c}\text { Case } \\
\text { number }\end{array}$ & Condition at commencement of treatment & $\begin{array}{c}\text { Total num- } \\
\text { ber of days* } \\
\text { on which } \\
\text { BAL was } \\
\text { injected }\end{array}$ & Final report on condition of case & $\begin{array}{l}\text { Number } \\
\text { of days } \\
\text { from first } \\
\text { injection } \\
\text { of BAL }\end{array}$ \\
\hline 11 & $\begin{array}{l}\text { Generalized angry erythema. Extensive weeping } \\
\text { over trunk and limbs. Exfoliation beginning } \\
\text { over shoulders, inner side of arms, thighs and } \\
\text { creases of abdomen; face and scalp clear. }\end{array}$ & 4 & Skin normal. & 69 \\
\hline 12 & $\begin{array}{l}\text { Exfoliative dermatitis, generalized except for hands } \\
\text { and feet. }\end{array}$ & 6 & $\begin{array}{l}\text { Skin satisfactory except on face and } \\
\text { hands which are still very dry and } \\
\text { scaly. }\end{array}$ & 35 \\
\hline 13 & $\begin{array}{l}\text { Erythema with commencing desquamation over } \\
\text { whole body. Exfoliation over lower third of } \\
\text { both legs. }\end{array}$ & 4 & Skin normal. & 23 \\
\hline 14 & $\begin{array}{l}\text { Generalized dusky red morbilliform rash with yel- } \\
\text { lowish powdery desquamation. Face swollen } \\
\text { and coarsely desquamating. Hands and feet } \\
\text { peeling and weeping. }\end{array}$ & 6 & All traces of dermatitis vanished. & 24 \\
\hline 15 & $\begin{array}{l}\text { Generalized erythema and edema. Scales on face, } \\
\text { neck and ears. Serous discharge from face. } \\
\text { Extensor surfaces of forearms and thighs dry } \\
\text { and scaly. }\end{array}$ & 8 & $\begin{array}{l}\text { Died } 17 \text { days after start of treatment } \\
\text { (skin reported much improved } 12 \\
\text { days after start of treatment). }\end{array}$ & \\
\hline 16 & Severe, diffuse weeping dermatitis. & 4 & $\begin{array}{l}\text { Skin practically normal in appear- } \\
\text { ance. }\end{array}$ & 3 \\
\hline 17 & $\begin{array}{l}\text { Generalized erythema with considerable itching. } \\
\text { Some exfoliation. }\end{array}$ & 2 & Skin practically normal. & 3 \\
\hline 18 & $\begin{array}{l}\text { Vesicular rash on arms and legs with edema and } \\
\text { crusting of exudate. Slight ulcerative stoma- } \\
\text { titis. }\end{array}$ & 7 & $\begin{array}{l}\text { Skin slowly returning to normal. } \\
\text { Dry and scaly all over. }\end{array}$ & 45 \\
\hline
\end{tabular}

* In several cases the injections were given in divided courses. For details see case reports.

** Local applications of BAL ointment given one month previously.

Condition on admission: Temp. $100^{\circ}$. Generalized dermatitis with much desquamation. Rash severe on abdomen, thighs and backs of legs. Back and face less severely affected; buttocks, feet, skin over patellae quite free.

2.11.43. More weeping of skin of thighs (front and back). Rest of body rough, with much crusting and desquamation. Penis edematous; elsewhere no edema. Temp. $100.2^{\circ}$, white count, 10,000 , eos. 14 per cent.

3.11.43. Temperature normal for first time since admission. Patient slept better. Skin around neck, in groins and inside of thighs definitely more inflamed; much desquamation. Face today, including ears, more involved. Tongue furred but moist. BAL $1 \mathrm{ml}$. injected into gluteal region.

4.11.43. Slight itchiness in back but slept well. Skin generally much improved. Less erythema and less oozing in groins and thighs. Back drying up. BAL $1.9 \mathrm{ml}$. given.

5.11.43. Skin still further improved. Erythema less and now limited to groins, scrotum and hypogastrium. Less crusting, but still considerable dry desquamation. Tongue cleaner. Appetite much improved during last 24 hours. BAL $2.0 \mathrm{ml}$. 6 and 7.11.43. No injections.

8.11.43. Much desquamation of skin generally, and hyperaemia of newly exposed dermis. Still complains of irritation, especially around shoulders. BAL $4.0 \mathrm{ml}$.

9.11.43. No weeping, except for very slight patches at upper end of sternum and on buttocks. Desquamation. Skin generally softer. BAL $2.0 \mathrm{ml}$.

10.11.43. Definite improvement; erythema more patchy with healthy skin between. Greatest improvement in thighs. Skin generally dry with finer desquamation, but some moisture still present in popliteal spaces and inside knees. BAL 2.0 $\mathrm{ml}$.

11 and 12.11.43. No injections.

12.11.43. Condition further improved. Skin more healthy. Patches of erythema and thickening less. Less swelling and desquamation on face and ears. Itch seems less marked and patient looks more comfortable. No weeping anywhere to-day.

13.11.43. BAL $2.0 \mathrm{ml}$.

14.11.43. Skin slightly better. Some irritation at upper 
CASE No. 1

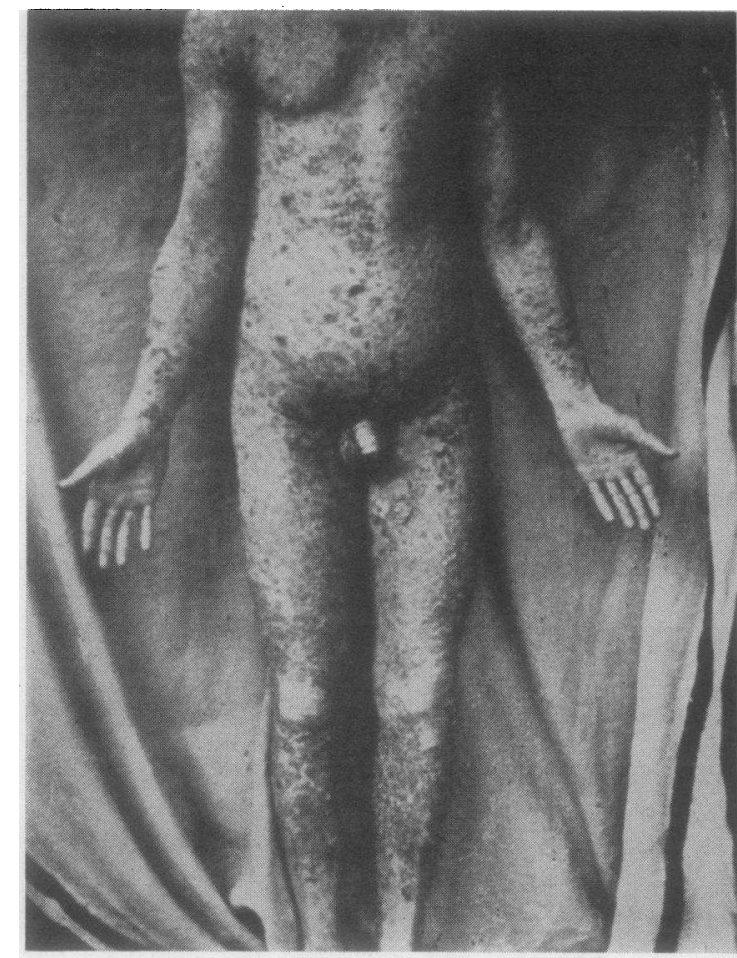

3rd November 1943.

end of sternum and on inner sides of thighs and popliteal spaces. BAL $2.0 \mathrm{ml}$.

15.11.43. BAL $2.0 \mathrm{ml}$.

16 and 17.11.43. No injections.

16.11.43. Skin unchanged. BAL ointment applied to patches of erythema below right nipple; irritation for 2 hours after application, but no certain change visible on 17.11.43.

18.11.43. Skin condition unchanged. BAL injections, morning $1.8 \mathrm{ml}$, evening $2.0 \mathrm{ml}$.

19.11.43. Since first few days after treatment started, the improvement has been gradual, and there has been no relapse. Erythema has not yet disappeared on body or limbs. No tendency to weeping except in popliteal spaces. BAL injections, $2.0 \mathrm{ml}$. morning and evening.

25.11.43. Skin much improved.

26.11.43. Erythema around neck and in popliteal spaces much improved.

1.12.43. Very marked improvement in skin. Erythema present only on inside of thighs and lateral aspects of chest.

3.12.43. Skin condition practically well. With exception of slight erythema on inner side of lower thighs, no dermatitis visible (Aspirin gr. $\mathbf{x}$ ).

General comments: There has never been any irritation or pain or tenderness at the site of injection. No ointments were used. Previous to 3.11.43 light diet given, but containing some meat, chicken, fish and eggs.

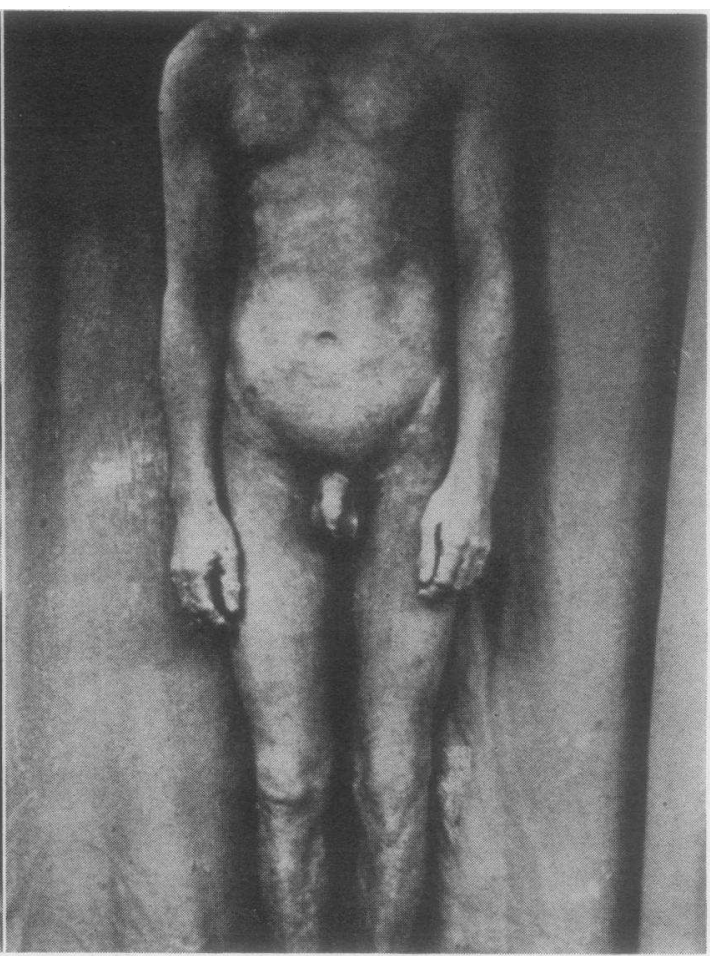

8th November 1943.

From 25.11 .43 to 30.11 .43 given casein biscuits ( $\equiv 60$ grams casein per day) in an attempt to accelerate healing. Note 1 by Professor Findlay. This patient seemed to make good recovery at first, but latterly improvement was slow and complete recovery was not more rapid than has occurred in equally severe cases treated with sodium thiosulphate intravenously and coal tar locally.

It is interesting to note the eosinophilia, seen also in other cases, and the fact that investigation of hepatic efficiency showed no evidence of liver damage.

Note by $R$. A. P. This case was seen throughout by R. A. P., and further estimations in addition to those mentioned in Note 1 were done in the Nuffield Laboratory of Biochemistry.

Blood urea. 2.11.43. $43 \mathrm{mgm}$. per $100 \mathrm{ml}$. 12.11.43. $28 \mathrm{mgm}$. per $100 \mathrm{ml}$. 22.11.43. $32 \mathrm{mgm}$. per $100 \mathrm{ml}$. 3.12.43. $28 \mathrm{mgm}$. per $100 \mathrm{ml}$.

The rather high value was therefore reduced after treatment.

$\begin{array}{cccc}\text { Blood proteins } & \begin{array}{c}\text { Total } \\ \text { grams } \\ \text { percent }\end{array} & \begin{array}{c}\text { Albumen } \\ \text { grams } \\ \text { percent }\end{array} & \begin{array}{c}\text { Globulin } \\ \text { grams } \\ \text { percent }\end{array} \\ 2.11 .43 . & 5.2 & 3.2 & 1.55 \\ 12.11 .43 . & 6.5 & 3.7 & \\ 22.11 .43 . & 6.34 & 3.7 & \\ 3.12 .43 . & 6.2 & 3.6 & \end{array}$


The blood proteins were low, though improving during treatment. Evidently cases showing much weeping should be treated like "burn" cases; there is a distinct indication for the administration of high protein diets.

Urinary creatine, creatinine and total nitrogen contents were determined daily with the technical assistance of R. W. Wakelin. Before treatment, urinary creatinine values were high, and creatine values of 1.2 grams per diem were found; by the start of the treatment however these abnormalities had disappeared. However, throughout the period in hospital, the total nitrogen content of the urine was high; unfortunately, owing to war-time conditions, it was not possible to get a proper estimate of food intake, but urinary $\mathrm{N}$ values of 20 grams and over, were recorded on several days, equivalent to protein values of 125 grams and more. There is again a suggestion here that negative balances occur in these patients (as in burns), a question which should be investigated when conditions are more favourable.

Photographs appended.

$\begin{array}{lr}\text { Case No. 2. Male, aged 28. } & \text { R. N. Hospital, } \\ \text { Chatham. } & \\ \text { History. } & \text { Surgeon Rear-Admiral C. F. O. Sankey } \\ \text { Date } & \text { and Surg. Lt. J. B. Sneddon. }\end{array}$

16.8.43. Primary chancre of coronal sulcus.

16.8.43 to 30.9.43. N.A.B. 3.75 grams. Bis. 2.2 grams.

24.8.43. Developed an erythema of arms and chest. Upon one occasion in mid-September some N.A.B. was given into the tissues of the arm; he had a painful arm for a day or so, and a lump remained.

7.10.43. Given an intravenous arsenical injection, and shortly afterwards the skin on the arm became red, itchy and began to peel. The following day the rash had spread to his face, and on the day of admission his face became swollen and all his skin became red and itchy. No vomiting or nausea. No malaise or diarrhea.

10.10.43. Admitted to hospital.

Past history.

Always prone to urticaria. Has suffered from epidermophytosis of the toes in the summer.

Family history. No allergic diseases.

Condition on admission. Skin : generalized erythema with commencing desquamation of the face, arms and legs. Some fissures around the toes becoming moist. Gross edema of the face, lips and eye-lids with a purulent conjunctivitis. Mucous membranes normal. Tongue clean and moist. Abdomen: Liver and spleen not enlarged. Heart and lungs: no abnormality discovered.

White count 11,200.

Differential count: Polymorphs 49 per cent Lymphs 20 per cent Large monos 6 per cent Eosinophils 25 per cent
A diagnosis of acute dermatitis was made.

Treatment in the first 24 hours was non-specific, fluids being pushed, but no local treatment given.

11.10.43 to 12.10 .43 . 3.5 grams BAL ointment applied. No erythema or change where the ointment was applied. General skin condition somewhat improved.

13.10.43. 2 grams BAL ointment. Intense subjective irritation after both applications, but no visible change.

14.10.43. Condition appeared to be deteriorating. Moist areas appearing on the neck, antecubital fossae and feet. Slight oozing on the chest. The condition of the skin continued to deteriorate during the next 3 days, and by 18.10 .43 large areas were moist and oozing. At that time a daily saline bath was instituted, and local treatment with ointment applied.

24.10.43. Developed a temperature of $102.6^{\circ}$ and an upper respiratory infection.

26.10.43. Pain in the chest and an infected sore throat. Started on a course of sulphadiazine. A total amount of 18 grams was given. Skin drying up and general condition improving.

10.11.43. Skin condition improved, but large areas on the arms, trunk and legs moist and desquamating. General condition rather poor.

12.11.43 to 17.11 .43 . $1.0 \mathrm{ml}$. BAL injected intramuscularly.

14.11.43. Quite definitely improved. Skin less scaly and erythema less. Stated that he noticed a difference even 1 hour after the first injection. No pain in the buttock and no skin eruption.

18.11.43. Skin had almost regained its natural elasticity, but there was still some secondary infection of the scalp and toes.

20.11.43. Severe generalized irritation and great difficulty in controlling scratching. However, this settled down with large doses of sedatives. The irritation continued, but got less until 30.11.43, when he developed an urticarial eruption on trunk.

3.12.43. Skin almost normal.

7.12.43. Skin normal apart from slight sepsis between the toes.

(Case seen by R. A. P. on 11.10 .43 . It should be noted that only slight improvement was effected by the inunction on 11.10.43, whereas a dramatic response followed the injection on 12.11.43.)

Case No. 3. Male. Harrow Road Hospital, London, W.9.

Date Major E. J. Mannix, R.A.M.C.

21.7.42. Early primary syphilis. W.R. ++ .

21.7.42 to 2.9.42. Novostab. 0.45 grams. N.A.B. 1.8 grams. Bis. 2.4 grams. Stabilarsan 2.4 grams.

16.9.42. Admitted to hospital with arsenical dermatitis. In hospital for $2 \frac{1}{2}$ months. Then sent to Convalescent Depot, which he left on 2.1.43. 
24.11.42 to 29.1.43. Bis. 3.0 grams.

1.3.43 to 29.5.43. Bis. 3.4 grams.

3.7.43 to 2.10.43. Bis. 4.4 grams.

20.11.43. Acetylarsan $1.5 \mathrm{ml}$. Bis. 0.2 gram. In good health. Skin well at this time. No other exciting factors.

21.11.43. Itching and spots on thorax.

24.11.43. Re-admitted to hospital. Generalized erythrodermia tending to vesiculation in parts. Treated with mist. alba and calamine cream.

4.12.43. Condition improving.

O.E. face: Dull pink with fine desquation. Minute fissures at angles of mouth and lower lip.

Trunk: Generalized pink, branny rash, stippled, or in places confluent.

Arms: Dry, branny rash.

Legs: Coarser exfoliation, most marked behind knees and on feet.

Hands: Backs thickened and dry. Right palm shows early peeling at base of thumb and index finger, and at wrist. Left hand, similar condition, beginning at base of thumb.

Fect: Soles greasy from ointment, yellowish, unbroken. Toe webs and nails unaffected.

No adenitis. Afebrile. No signs of visceral disease or enlargement. Knee jerks +++ . Faint tremor of extended hands. Conjunctivae anaesthetic to coarse pressure. Soft palatc scratched without retching. Suggestive anaesthesia to pin-prick.

5.12.43. $2 \mathrm{ml}$. BAL intramuscularly.

6.12.43. $1 \mathrm{ml}$. BAL intramuscularly.

14.12.43. No evidence of any skin lesion.

(Seen by W. J. O'D., R. A. P., R. H. S. T., and D. I. W. on 4.12.43, and by W. J., O'D. and D. I. W. on 14.12.43.)

Case No. 4. Male. Harrow Road Hospital, London, W.9.

Date

Major E. J. Mannix, R.A.M.C.

12.10.43. Early primary syphilis. W.R. ++.

14.10.43 to 13.11.43. N.A.B. 3.45 grams. Bis. 1.2 grams.

20.11.43. Mild icterus and rash. Malaise, nausea, heartburn and vomiting (once). No diarrhea or joint pains. Admitted to hospital.

2.12.43. Developed generalized maculo-papular eruption. Complained of nocturnal skin irritation. Seen by Command Dermatologist and diagnosed as arsenical dermatitis.

Condition on admission: Yellow sclerae. Faintly yellow trunk and limbs. A generalized rather coarse eruption, mostly on hips, characterized by irregularly shaped pink splashes, dry and rough, finely papular or small, flat, irregular plaques, with a whitish surface; inside of right arm abraded and red, with sweat dripping from axilla, bluish-pink splashes on shins. Webs of fingers, wrists and penis clear.

8.12.43 to 11.12 .43 . One ampoule BAL intramuscularly b.d. for 3 days. Rash had been subsiding with some desquamation before treatment started.

9.12.43. Areas of thighs originally clear of rash showed new eruption similar to rest of body.

10.12.43. No irritation. Rash on thighs subsiding.

11.12.43. Rash improving, desquamation well marked.

14.12.43. Rash disappeared. Residual pigmentation present.

28.12.43. Discharged from hospital. No recurrence of eruption, though residual pigmentation persists. The jaundice followed the usual course, and was responsible for the long stay in hospital. There was no general reaction to the injections, and local reaction was limited to slight heat, tenderness and stiffness of the buttock, appearing in 6 hours and disappearing within 24.

31.12.43. Skin smooth, soft and clear, with scattered brown guttate pigmentation of the trunk. Fit for duty.

Serum bilirubin estimations were carried out at intervals to determine whether $\mathrm{BAL}$ therapy was exerting any obvious effect on the jaundice. The results, which are given below, do not reveal any striking effects.

Date

6.12 .43

7.12 .43

8.12 .43

10.12 .43

13.12 .43

16.12 .43

19.12 .43

(Seen by W. J. O'D., R. A. P., R. H. S. T., and D. I. W. on 4.12 .43 and by W. J. O'D. and D. I. W. on 31.12.43.)

Case No. 5. Female, aged 33. Royal Free Hospital, London, W.C.1.

Dr. M. M. Share.

Past history. Diphtheria at age of 10 .

Syphilis first diagnosed September, 1942, when in hospital suffering from gummatous ulcers of left thigh and calf. Wasserman 1942, strongly positive. Received 3 injections of arsenic (neoarsphenamine, 0.3 gram, 0.3 gram, and 0.45 gram) together with bisocyl. 21 to 28.10 .42 . 0.9 gram neo-arsphenamine, and 2 injections bismuth. 4.11.43. Re-admitted to hospital with 'severe generalized arsenical dermatitis affecting whole body from scalp to toes.' 20.1.43. 'Good recovery and discharged.'

Date

7.6.43. Admitted to surgical ward with (1) fracture of right femur, (2) compound fracture of left tibia and fibula and (3) laceration of calf and right forearm, having fallen from third floor window. While in hospital no active anti-syphilitic treatment, but advised to attend V.D. clinic later.

17.12.43. Attended clinic and received N.A.B. 0.15 gram with 0.45 thiostab.; adexolin ordered. 
22.12.43. Returned with second attack of dermatitis. Very distressed and ill. Temp. 96 ${ }^{\circ}$, P. 132. Admitted to ward and given thiostab. 0.9 gram in $20 \mathrm{ml}$. glucose. Stated skin irritation began few hours after arsenic injection. General erythema, face flushed and swollen, slight peeling on face and back of neck, eyes puffy, legs edematous and flushed, with early desquamation.

24.12.43. More comfortable but more desquamation, soreness under axillae and breasts. Given thiostab. 0.9 gram in $20 \mathrm{ml}$. glucose.

26.12.43. Condition worse. General exfoliation.

26 to 28.12 .43 . BAL injections, $2 \mathrm{ml}$. twice daily.

29.12.43. Complained of pain at site of injection (gluteal muscle). General exfoliation, but face improved.

30.12.43. Much improved. Face nearly clear. Hands peeling and sore. Back very sore.

5.1.44. Abscess R. gluteal region. Skin clear except for soles of feet.

14.1.44. Skin now completely clear.

Abscess of L. gluteal region. Healed well with simple treatment.

No relapse of skin condition noted at any stage.

Note 1: Dr. Shaw has stated (19.1.44) that BAL cleared up the clinical condition in this case of arsenical dermatitis with great rapidity.

Note 2: Note the small amount of N.A.B. causing damage. (Seen by R.H.S.T. on 20.12.43.)

Casc No. 6. Male.

Hope Hospital, Pendleton, Salford.

Date Dr. A. Gill.

18.11.43 to 13.12.43. Stabilarsan 5.25 grams. Bismuth 1.2 grams.

16.12.43 to 22.12 .43 . Thiostab. 1.2 grams daily. Generalized exfoliative dermatitis.

26.12.43 to 28.12.43. BAL injected.

1.1.44. Exfoliation almost complete on trunk and arms. Patient began to feel a little better. Apyrexial. Skin dry. No secondary sepsis.

4.1.44. Mild rigors.

5.1.44. Died suddenly.

6.1.44. Autopsy showed (a) Terminal bronchopneumonia. (b) Arsenical dermatitis. No evidence of liver cirrhosis.

Case No. 7. Male.

Military Hospital, Preston.

Date

Major Laird, R.A.M.C.

15.1.43. Chancroid. Dk. ground neg. (3 times). Eusolsulphanilamide powder $3 / 52$.

7.10.43. Maculo-papular rash. Small penile sore at fresh site. Generalized adenopathy. Dk. ground +

15.10.43. Kahn + .

18.10.43. Kahn ++ .
8.10.43 to 7.12.43. Neo-arsphenamine 6.0 grams. Bis. 2.4 grams.

23.12.43. Admitted to hospital with exfoliative dermatitis. All areas including scalp involved. Exfoliation moderately severe. Conjunctivitis and blepharitis present.

26.12.43. Temp. $99^{\circ}$. General condition satisfactory. No change in skin. Pocket of pus superficial to left upper eyelid.

30.12.43. Abscess outer canthus right eye incised.

2.1.44. Skin improved. Abscess just below left eyebrow. Multiple folliculitis. Treated: Calamine and oil. 2 per cent Argyrol to eyes.

On examination: Movement restricted by soreness. Slight cough. Tongue. Mind clear, slow. Head: Pink. General, fine branny desquamation; styes, right and left. Small domes of pus on right and left upper lids. Small dry pustules on face.

Upper limbs: Dry, shaggy with peeling. Deep, thick, dry peeling of palms and fingers. Slight folliculitis. Dry and pink round elbows.

Back: Dry; pink; very fine universal peeling. Erupting boils at root of neck and above right shouldef Sparsely scattered follicular scabs between scapulae.

Front: Harsh and dry. Multiple folliculitis. Boils on mid thorax, groins, pubis and perineum. Feet: Extensive deep, dry peeling, spreading to toes.

Legs: Coarse, dry peeling. Small boils in both popliteal fossae. Long operation scar astride right thigh (from accident to right femur, age 8). No urethritis. Teeth fairly good. No icterus.

Diagnosis: Severe arsenical dermatitis, complicated by skin sepsis.

7.1.44. Skin still improving.

9 to 11.1.44. BAL, 2 ml. b.d. Skin improving quickly.

14.1.44. Skin very greatly improved. Multiple abscesses increasing in number.

18.1.44. Skin clear of all scaling and erythema, except for scalp and feet. Residual sepsis persisted for 7 weeks.

(Seen by W. J. O'D. and D. I. W. on 3.1.44.)

Case No. 8. Female.

St. Mary's Hospital, Portsmouth.

Dr. A. Murray Stuart.

Arsenical dermatitis.

No previous history of skin affections or sensitivities.

Occupation: Housewife.

Date

22.10.43. Attended V.D. clinic with history of labial sore 10 months previously. Mucous patches on lower lip.

22.10.43. Wasserman strongly positive.

29.10.43. Wasserman strongly positive. 
CASE No. 8

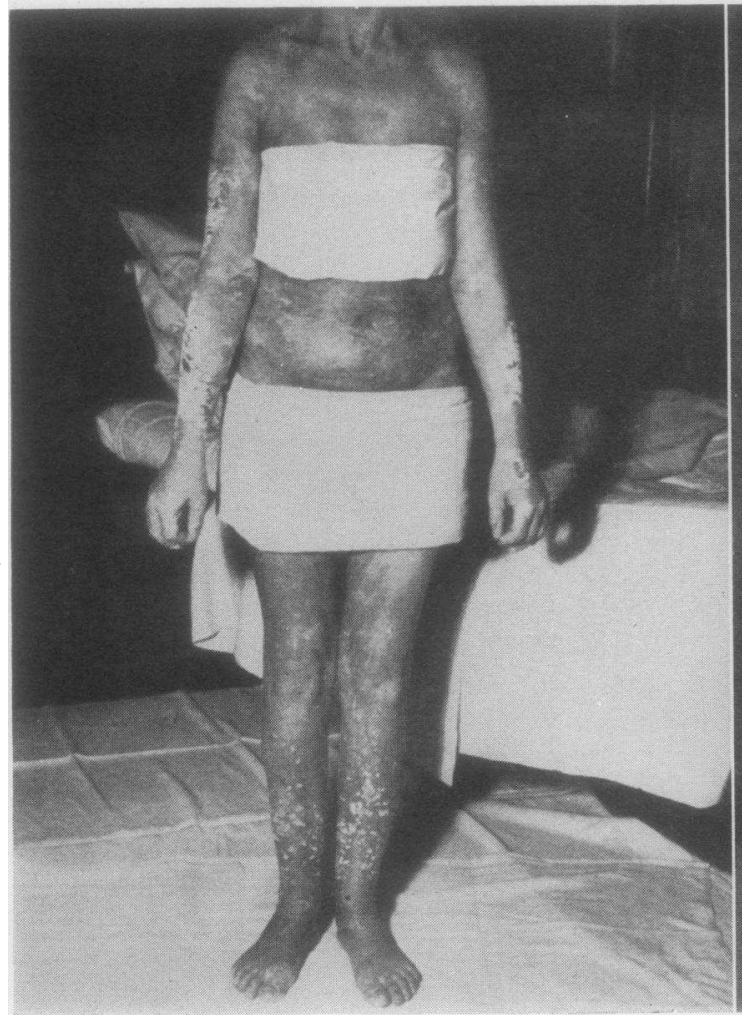

15th January 1944.

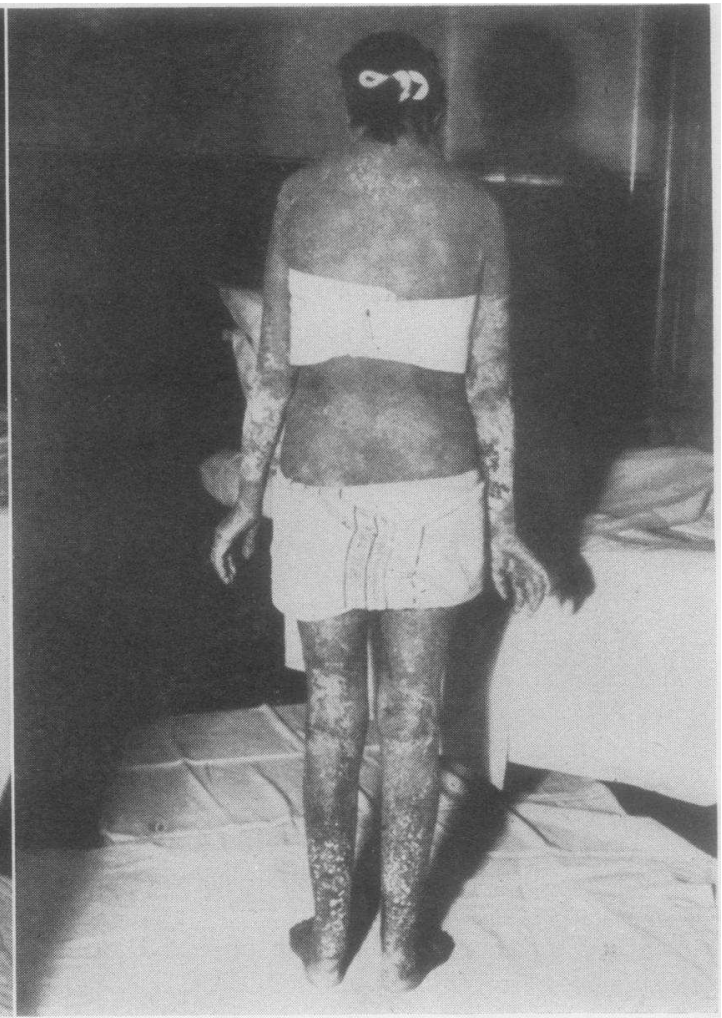

15th January 1944.

Taken 11 days before first injection.

5.11.43 to 22.12.43. Novostab. 4.5 grams. Chlorostab. 1.6 grams.

31.12.43. Dermatitis on chest, axillae and groin; treated with calcium thiosulphate.

7.1.44. Dermatitis very extensive; again treated with calcium thiosulphate and borocalamine lotion.

13.1.44. Admitted to hospital with generalized exfoliative dermatitis affecting the whole body, except the soles of the feet. Oozing on scalp, inner sides of forearms, inner sides of thighs and legs. Exfoliation of the rest of the skin. Treated with sodium thiosulphate, $10 \mathrm{ml}$. daily, and 1 ml. Hepatex weekly.

22.1.44. All treatment discontinued except calamine lotion externally.

26.1.44 to 28.1.44. BAL injected; $2 \mathrm{ml}$. daily.

1.2.44. No improvement yet noted in the condition of the skin, which is still moist in some areas and exfoliating in others. Itching a little less. Temperature, which had risen several times to as high as $101.6^{\circ}$, has subsided to a maximum of $99.8^{\circ}$.

2.2.44 to 10.2.44. Another 9 injections of BAL given, $2 \mathrm{ml}$. daily.
11.2.44. Patient now improved very considerably. Says she feels quite well. Temperature remains normal. All the skin areas are dry. Still some desquamation on the nape of the neck, abdomen and backs of forearms. Abdomen markedly pigmented.

14.2.44. Improvement maintained until 14.2.44, when she began to develop axillary and inguinal adenitis with some superficial inflammation of the left breast. Areas of the scalp and forearms have again become slightly moist. Diagnosed as a secondary staphylococcal infection. Sulphathiozole, 4 grams daily, given for 5 days. Gentian violet applied.

2.3.44. Skin clear except for lichenification of backs of hands and left shoulder.

11.3.44. Discharged. Photographs appended.

Case No. 9. Male. Harrow Road Hospital,

London, W.9.

Date

Major E. J. Mannix, R.A.M.C.

2.2.44. Admitted to hospital, suffering from arsenical dermatitis. 
Case No. 9

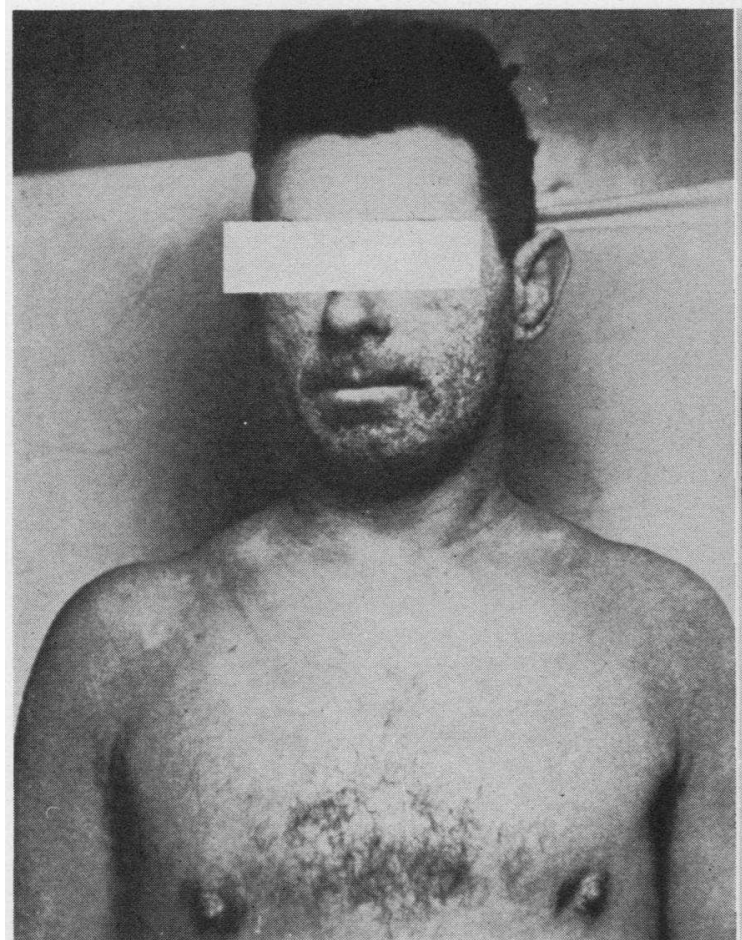

5 Feb. 1944.

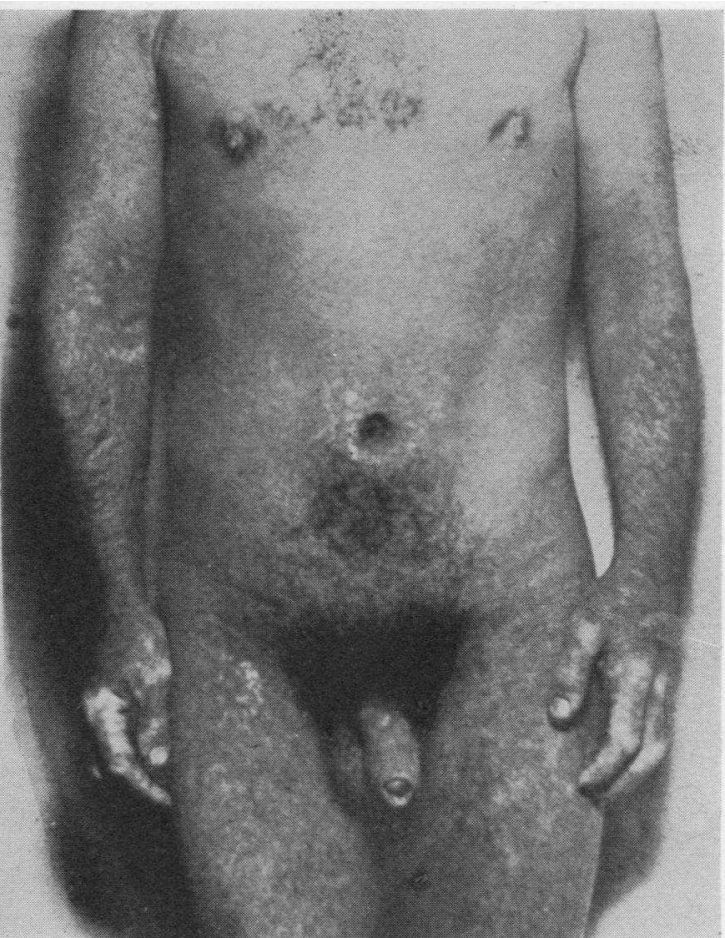

5 Feb. 1944.

Taken before treatment, on day of first injection of OX.217.

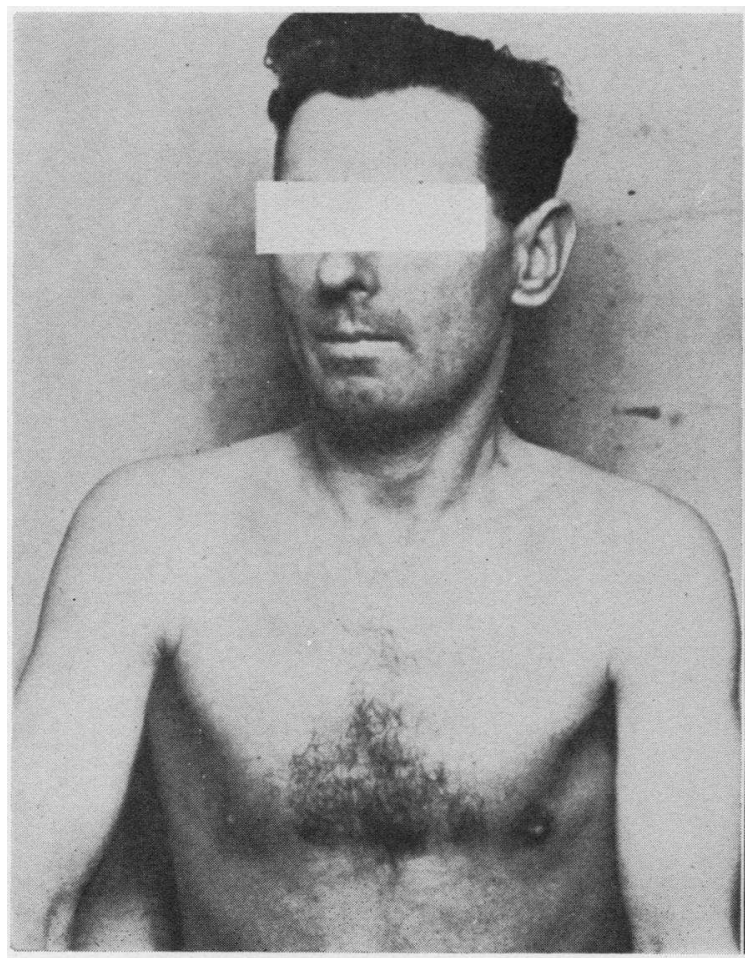

16 Feb. 1944.

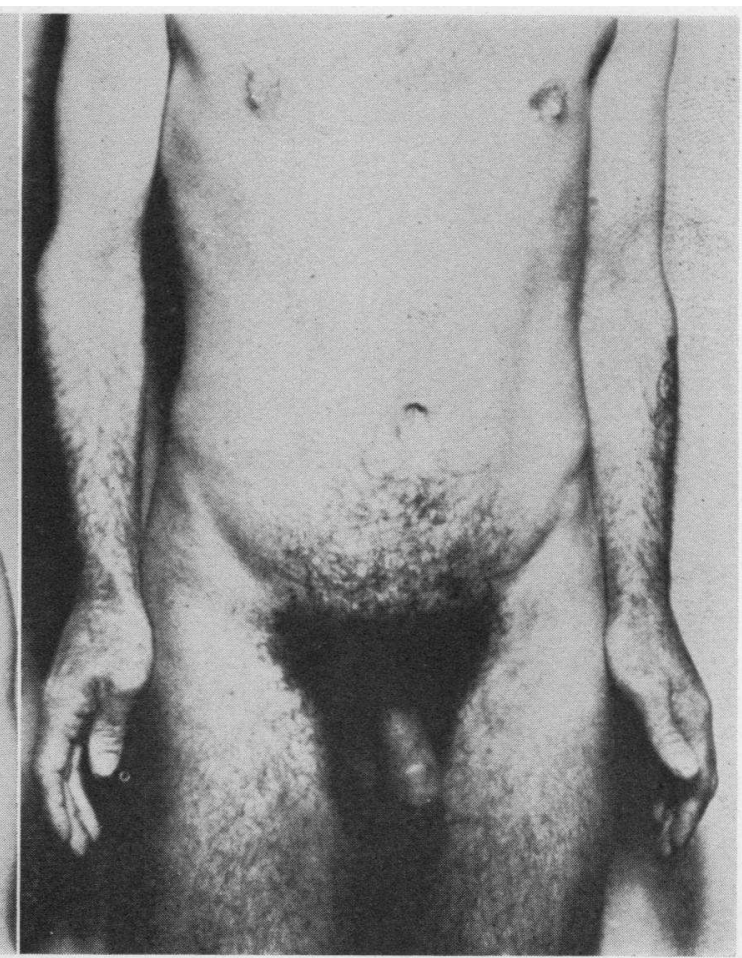

16 Feb. 1944.

Taken 11 days after first injection of OX.217. 
History: Syphilis 18.9.43. Previous diseases: Nil. Family history of allergy: Nil.

Occupation: Acetylene welder.

Treatment: With N.A.B., 1st course 22.10.43 to 23.12.43. Total arsenic 4.05 grams. Kahn weak + .

Second course stabilarsan 21.1.44 to 0.45. 25.1.44 to 0.6. 1.2.44. Arsenical dermatitis.

On admission: Suffered from headache, general malaise, moderate pruritus. Temp. $100^{\circ}$. Tongue slightly coated. Conjunctivae normal. Skin: With the exception of the palms and soles, which were clear, and the chest on which there was a general erythema, there was a generalized dusky erythrodermia of whole body with fine desquamation tending to be coarser on the face.

Patient treated with pot. permang. baths, calamine cream and mist. alba.

5.2.44 to 7.2.44. $2 \mathrm{ml}$. BAL injected daily.

After 3rd injection skin showed marked improvement, erythrodermia subsiding generally. Palms and soles began to peel. Complained of headache and pain behind eyes.

10.2.44. Skin condition showed signs of relapse, and daily urine output dropped to $850 \mathrm{ml}$.

10.2.44 to 12.2.44. BAL $2 \mathrm{ml}$. daily. With exception of slight erythema of chest and desquamation on palms and soles the skin appeared normal. Urine output, however, remained subnormal. Large quantities of fluid ordered, and output rose rapidly, on one occasion reaching $2900 \mathrm{ml}$. in 24 hours.

15.2.44. W.R. neg.

On the 19th day after commencement of injections patient complained of nausea and weakness, urine output again dropped to $800 \mathrm{ml}$., and showed traces of bile and albumen. On 22nd day developed generalized jaundice.

On 28th day (4.3.44) following commencement of treatment, a rash appeared on the body, most marked on the thighs, lower abdomen and back. A further course of three $2 \mathrm{ml}$. injections of BAL was given.

Following the second injection the rash completely disappeared.

Photographs appended.

Case No. 10. Female, aged 23. Royal Infirmary, Derby.

Date

Dr. H. R. M. Richards.

30.12.43. Admitted to hospital with extensive secondary syphilitic ulceration of the vulva. Severe headaches. 8 to 9 months pregnant. (Next day,

CAse No. 10



14th Feb. 1944.

Taken on day of first injection of OX.217.

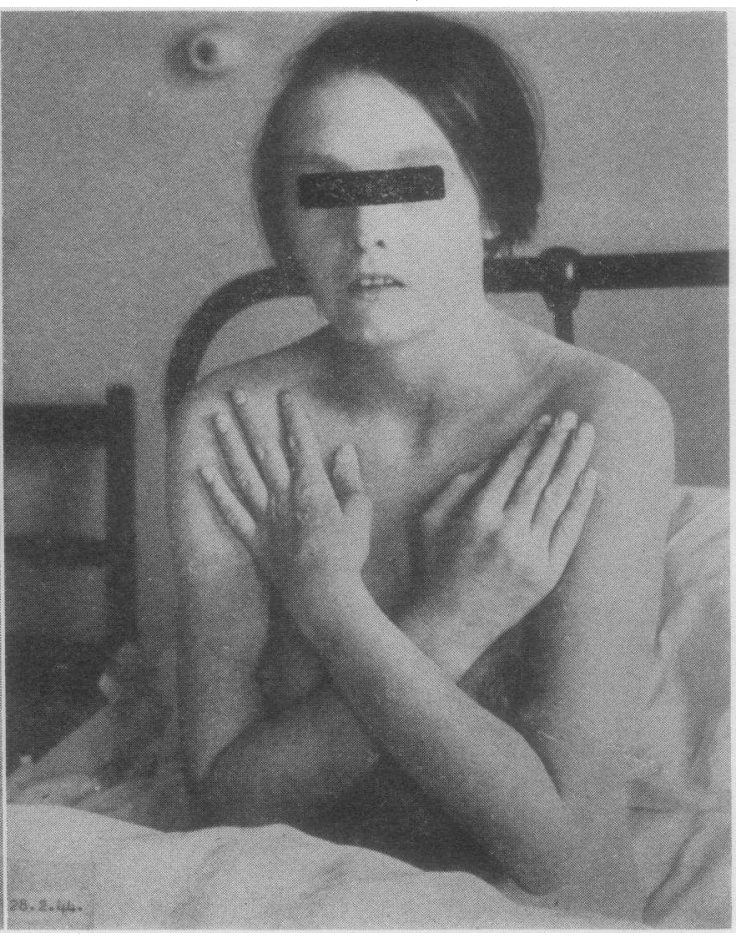

28th Feb. 1944.

Taken 14 days after first injection of OX.217. 


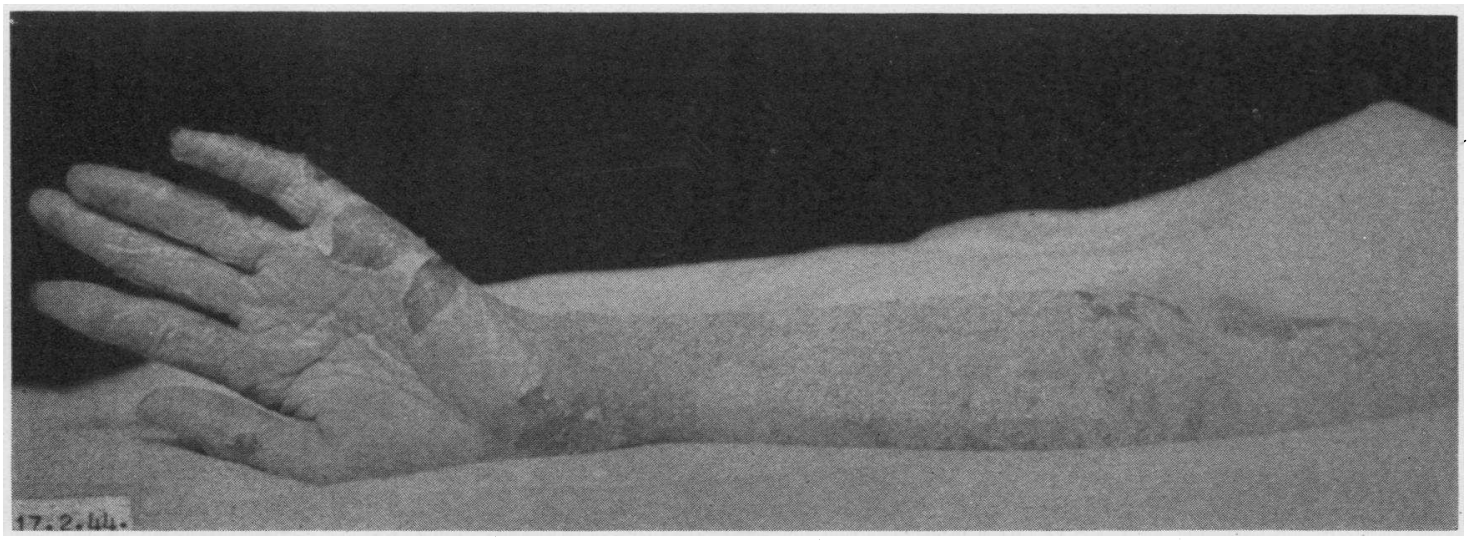

17th Feb. 1944. 3 days after first injection of OX.217.

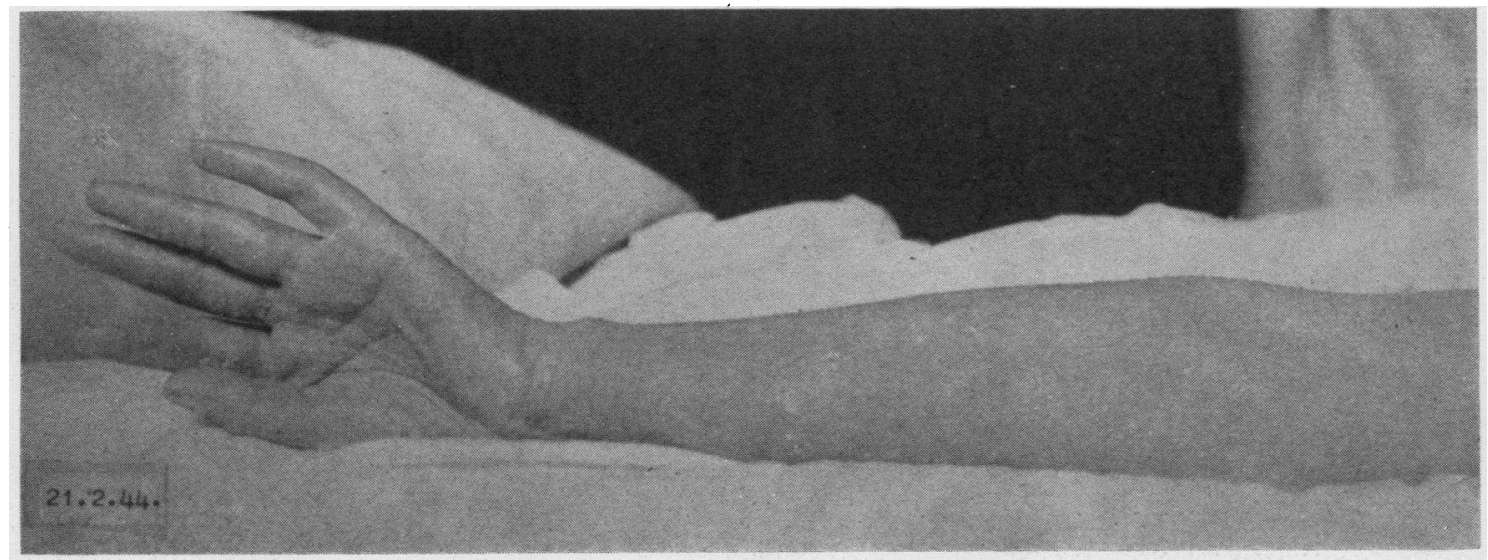

21st Feb. 1944. 7 days after first injection of OX.217.

delivered of marasmic baby which lived 4 hours.) Treated with N.A.B. 0.3 gram. Bismuth 0.2 gram.

5.1.44. N.A.B. 0.45 gram.

13/20/27.1.44. N.A.B. 1.35 grams. Bismuth 0.6 gram.

3.2.44. Bismuth 0.2 gram. Irritation and erythema of forearms.

9.2.44. More acute and more generalized pruritus. Erythema spread to chest and thighs with some edema of fingers.

10.2.44. Edema spread to forearms and desquamation began, skin of forearms and thighs becoming livid. Felt cold. Irritation more intense, malaise, loss of appetite, some nausea.

12.2.44. Rash more extensive and severe. Skin livid, leathery and desquamating. Increased swelling of fingers and limbs, pruritus and malaise increased. Condition rapidly deteriorating.

14.2.44. Edema spread to face. Dermatitis generally more intense, desquamation increasing, serous discharge from chin, forearms and hands.

14.2.44 to 16.2.44. BAL injections.

15.2.44. Bullae forming on hands and feet, copious discharge from chin, upper and lower limbs and, to lesser extent, from trunk. Desquamation spreading on face, slight conjunctivitis. Tongue clear.

17.2.44. Improvement in skin condition and appetite. Oozing reduced, and edema of face and arms subsiding.

18.2.44. All lesions dry except on knees and feet. Skin looks healthier despite generalized desquamation and exfoliation of hands and feet. Secondary infection of forearms. Temp. 102.6 . Swab from skin showed staphylococci, streptococci and B. coli.

19.2.44. Edema much reduced, but painful fissures on forearms. Temp. $103^{\circ}$. Slight oozing still on chin, feet and knees. Ungt. thiazamide applied to skin.

21.2.44. Marked improvement. No edema. No sepsis. Skin lighter in colour and desquamation much less marked. Temp. $100^{\circ}$. Feels much better and warmer. Improvement maintained.

28.2.44. Skin dry and returning to normal colour. Scattered scaling, particularly in scalp. Temp. normal, general condition and appetite much improved. Photographs appended. 
Case No. 11. Female, aged 30. Queen Alexandra' Military Hospital, Shenley.

Major M. Bolton, R.A.M.C. No previous history of any skin affection or sensitivity.

Date

7.1.44. Secondary syphilis manifested by vulval sores, laryngitis, mucous patches. No secondary rash. (No concomitant gonorrhea. No sulphonamides given.) Dk. ground ++ . W.R. ++ .

The skin of the face was dry and scaly on admission; she declared this was its usual condition.

8.1.44 to 2.2.44. N.A.B. 2.7 grams. Bismostab. 8 grams. No reactions. Complained that about 6 hours after each injection (except first) she felt feverish. Stated she had rash on both anticubital fossae from 26th Jan. (not observed by M.O.).

3.2.44. Vesicular eruption of arms and shoulders with general erythema and suffusion of conjunctivae. Temp. 99. $2^{\circ}$. Gradual increase in extent of vesiculation with maintained low grade fever. Treatment: Zinc cream twice daily and sodium thiosulphate by mouth daily. Pot. permang. baths.

16.2.44. Condition before treatment: Patient just out of pot. permang. bath. Plump, well-nurtured, depressed, lachrymose.

Face and scalp: No abnormality.

Conjunctivae: Clear, no suffusion, no icterus.

Neck: General erythema with blotchy areas of dusky blue.

Trunk and limbs: Generalized angry erythema, with scattered patches dusky blue. Weeping extensive over trunk and limbs. Exfoliation beginning over shoulders, inner side of arms and thighs and creases of abdomen. Exudate pouring from these areas. Considerable general edema and subcutaneous edema of feet and ankles.

16 to 19.2.44. BAL injections : 16 and $17 \mathrm{Feb} .2 \mathrm{ml}$. daily. 18 and 19 Feb. 2 ml. b.d.

Other treatment: pot. permang. baths.

23.2.44. Skin better, drier, with less edema. General condition fair. Complained of pain and great tenderness in both buttocks over site of injection.

25.2.44. Old skin peeling off. General condition poor. Circulation sluggish, with peripheral cyanosis. Edema much less marked.

29.2.44. Skin continues to improve. Obvious abscess R. buttock. Swelling and pain in L. buttock. General improvement.

6.3.44. Still some dry desquamation, with generalized erythema. Kahn test negative.

9.3.44. Skin as on 6.3.44. Abscesses incised and pus evacuated.

14.3.44. General condition markedly improved. Skin generalized dusky red. Scaly patches on forearms and shins, otherwise normal.

28.3.44. Abscesses healed. Skin less erythematous.

25.4.44. Skin normal.

(Seen by D. I. W. on 16.2.44.)

Case No. 12. Male, aged 47. Military Hospital,

Date

Preston.

Major Laird, R.A.M.C.

9.11.43. Primary syphilis. Dk. ground +. W.R. negative.

10.11.43 to 6.1.43. N.A.B. 5.85 grams.

12.11.43. Papular erythematous rash on front of forearms and thighs. Treated for scabies. Gives history of eczema behind ears in 1927 while working with tar boilers.

3.2.44 to 2.42.44. N.A.B. 2.25 grams.

24.2.44. Developed eczema of both arms, and arsenic was stopped.

14.3.44. Admitted with exfoliative arsenical dermatitis. On admission, marked scaling of the scalp and a generalized dermatitis with commencing exfoliation and weeping at the flexures. Temp. $100.4^{\circ}$. Hands and feet not involved.

Treatment: Bed, calamine cream to skin. Hair cut on scalp and ung. sulph. et salicyl. applied.

15.3.44. Skin unchanged. Temp. $98.6^{\circ}$. Complained of sore throat and numbness of hands. Throat slightly infected. Slight swelling of dorsum of hands.

White count, 7400. Polymorphs 50.3 per cent L. lymphos 5.6 per cent S. lymphos 17.6 per cent Eosins 25.3 per cent Basos 0 per cent Trans $\quad 0.6$ per cent Monos $\quad 0.3$ per cent

Phenobarb. gr. 1 nocte.

16.3.44. On examination:

Head: Hair short and matted by exudation: retroauricular streptococcal fissures.

Face: Clear. No icterus of conjunctivae.

Arms and trunk: Dusky-red colour. Vesiculation and fine scaling interspersed with areas of complete epidermal loss and weeping. No involvement of palms of hands. Vesiculation of dorsum of hands.

Feet: Normal.

Legs: Gross shedding of skin of thighs and lower abdomen, several flakes up to three inches in diameter. Fine scaling only of legs.

Diagnosis (D. I. W.) : Severe exfoliative arsenical dermatitis; a little less severe than Case No. 9 or No. 11.

Prognosis (D. I. W.) : 8 to 10 weeks.

17.3.44. Temp. $99^{\circ}$. Exfoliation now generalized, except for hands and feet.

18.3.44. Skin unchanged. BAL 2 ml. b.d.

19.3.44. BAL 2 ml. b.d. Less weeping. 
20.3.44. Skin still exfoliating ++ . Small abscess in both axillae. Shaved and kaolin applied. BAL 2 ml. b.d.

21.3.44. BAL $2 \mathrm{ml}$. b.d. Skin still desquamating, but improving slightly.

22.3.44. BAL $2 \mathrm{ml}$. b.d. Small abscess pubic area.

23.3.44. BAL $2 \mathrm{ml}$. b.d.

24.3.44. Abscess rt. axilla draining; spirit meth. and powder applied.

28.3.44. Hands and feet now desquamating. Skin improving steadily. Abscess left axilla dry.

30.3.44. Condition satisfactory. Sepsis in axillae and in pubic region now practically resolved.

31.3.44. Still desquamating.

1.4.44. Skin greatly improved.

4.4.44. Up for half an hour.

12.4.44. Exfoliation complete. Scalp, face and flexures still scaling.

22.4.44. Face and hands still very dry and scaly. Remainder of skin satisfactory.

Both this case and Case No. 7 appeared to be seborrhoeic types.

Both had been treated for scabies. This case has done very well but terminal condition of skin is not so satisfactory as that of Case No. 7. There has been no dramatic improvement of skin that could be attributed to the treatment (seen by D. I. W. on 16.3.44.)

Case No. 13. Female, aged 20.

Date

Department of Health, Rotherham.

Dr. R. C. Wofinden.

16.12.43. Primary chancre of 1t. labium majus of 1 month's duration. Dark ground + . W.R. ++ . $\mathrm{Kahn}++$.

6.1.44 to 10.2.44. Stabilarsan 2.7 grams. Bis. 1.2 grams.

17.2.44. Acetylarsan $3 \mathrm{ml}$. Bis. 0.2 gram.

On the evening of 17 th February patient complained of pain in legs and insomnia. Later, legs began to swell.

18.2.44. Erythematous rash covering whole body, with swelling of face and further swelling of legs. Calamine lotion applied.

24.2.44. Admitted to hospital.

Condition on admission: Afebrile. Pulse 110. R. 20. Marked swelling of face and legs. Commencing desquamation with erythema over whole body including face, arms and legs. Exfoliation over lower thirds of both legs. Thiostab. 0.45 gram i.v., glucose and calamine lotion. No previous skin diseases, no family history of allergy. Patient complained of irritation of

CASE No. 13

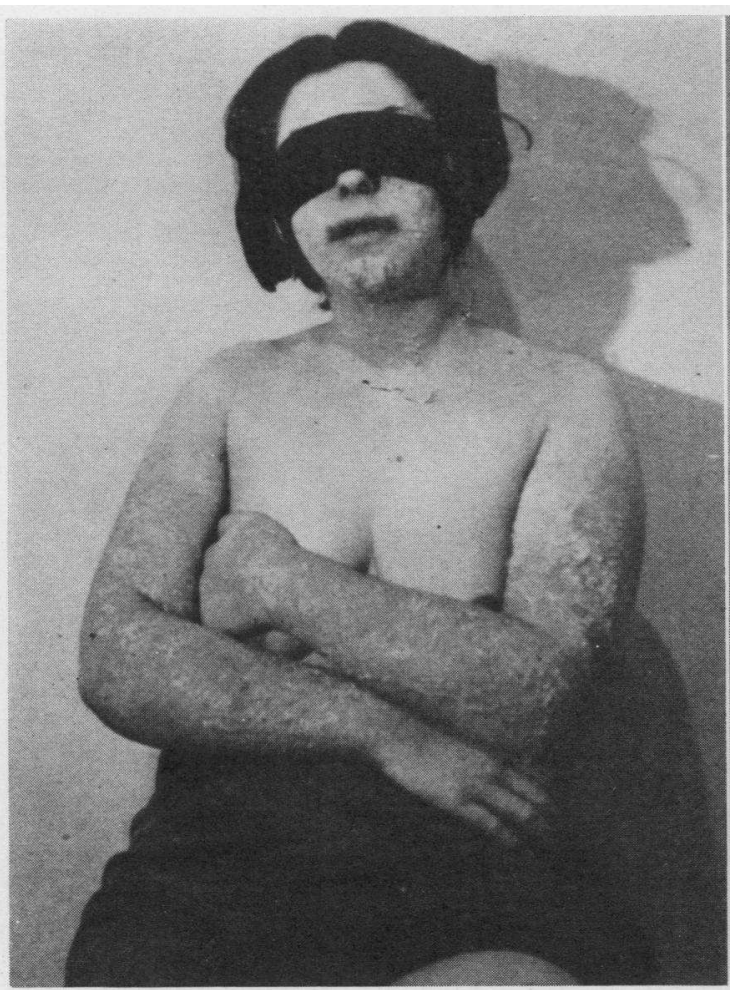

Taken before treatment.

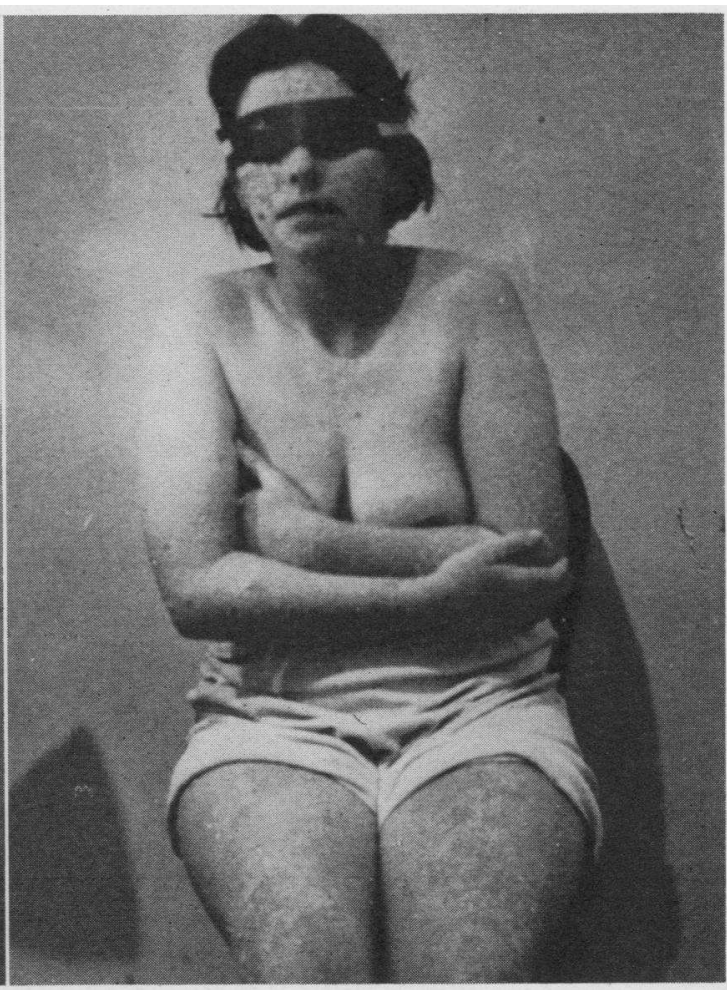

Taken 3 days after first injection. 
arms. No malaise. Appetite good. No nausea, vomiting or headache. Conjunctivae and tongue normal. No diarrhea. No urine passed first 24 hours after admission. No enlargement of liver or spleen. No albuminuria. No jaundice.

26.2.44. Skin condition unchanged.

29.2.44. Two injections of BAL given. Calamine lotion locally. Fluids ++ . Aperients.

1.3.44. Two injections BAL. All edema disappeared.

2.3.44. One injection BAL. Complained of malaise, throat felt slightly sore in afternoon. Temp. 100.5 . Pulse 110. R. 20. O/E throat clear. Chest clear. Sixth dose withheld.

3.3.44. Sixth BAL injection given, general condition improved. Temp. $100^{\circ}$. Pulse 110 . Most impressive feature was dryness.

6.3.44. General condition satisfactory. Skin remains dry, and normal skin is appearing beneath exfoliations.

8.3.44. Very depressed. Complained of poor night and being 'wet through' all night. Temp. $97^{\circ}$. Pulse 110. R. 20. Appearances suggestive of relapse.

9.3.44. General condition much improved. Skin dry again and erythema subsiding. Infected crusted patches about $3 / 4$ in. in size on each cheek. Starch and boracic poultices applied to cheeks. Pin-point pustules on creases of both palms; treated with fomentations.

11.3.44. Skin condition still improving. BAL not given. Cheeks and palms of hands gradually improved during next few days, and temp. remained normal.

14.3.44. Skin practically recovered.

17.3.44. Oatmeal baths given with rapid removal of remaining desquamation.

23.3.44. Face, body, arms and legs clear. Pain and induration in left buttock.

26.3.44. Fluctuating swelling of upper and outer quadrant of left buttock. Patient afebrile.

28.3.44. Spontaneous discharge of pus through small opening. Incised, evacuated and packed.

31.3.44. Discharged. Still some discharges from buttock.

Note: Dr. R. C. Wofinden has added the following comments (8.7.44).

1. The rapid disappearance of the edema and dryness of the skin following the first 2 injections were quite impressive.

2. The patient had practically recovered within a period of 2 weeks from commencement of treatment. Photographs appended.

Case No. 14. Male. Harrow Road Hospital, London, W.9.

Major E. J. Mannix, R.A.M.C.

Diagnosis: Arsenical dermatitis.

Past history of skin conditions: Nil

Family history: Nil.
Present history: 5.1.44 N.A.B. 0.30 gram. 12.1.44 N.A.B. 0.30 gram.

Following the second injection an arsenical reaction was observed. There was a scarlatiniform rash of the hands and feet. Treated with sodium thiosulphate; small doses of N.A.B. were ordered.

Date

19.1.44 to 16.2.44. N.A.B. 2.85 grams.

18.2.44. Developed arsenical dermatitis. First appeared as a blotchy scarlatiniform rash on forearms and hands, less marked on feet.

26.2.44. Slight fissuring and desquamation on dorsum of both feet. Calamine cream applied.

29.2.44. Rash frankly moist and weeping Sod. thiosulphate stopped.

4.3.44. Admitted to hospital.

Condition on admission: Generalized, dusky, red morbilliform rash with yellowish powdery desquamation. The face was swollen and coarsely desquamating. The hands and feet were peeling, and the underlying new skin was erythematous and weeping. The whole picture was complicated by secondary infection. Calamine cream was ordered for the whole body.

6.3.44 to 8.3.44. BAL $2 \mathrm{ml}$. b.d.

9.3.44. Erythema fading. Much fine desquamation all over body. Hands and feet still weeping.

12.3.44. Generalized weeping worst on lower abdomen and thighs.

12.3.44 to 14.3.44. BAL 2 ml. b.d.

15.3.44. Marked improvement. Hands and feet still peeling and weeping. Erythema on body fading. Desquamation on face clearing up. A number of pustular lesions scattered over the body, particularly on the back and limbs. Ung. resorc. 5 per cent, with sulph. Still a severe degree of pityriasis capitis. Ung. pet. with ol cadi.

20.3.44. Hands and feet no longer weeping.

23.3.44. Allowed up for short time. Complains that feet are tender and painful.

27.3.44. Pustular rash still persisting, but pustules not so numerous.

30.3.44. Ung. pet. with sulph. (scalp). From this until discharge treatment was only for the pustular acneiform lesions on back; all traces of arsenical dermatitis had disappeared.

22.4.44. Discharged.

Case No. 15. Male, aged 21. Belmont Road Hospital, Liverpool. Dr. C. McGibbon.

Past history: No skin trouble. No familial allergy. Generalized secondary macular syphilitic rash with penile chancre 6 weeks ago. Elèven injections of stabilarsan at intervals of twice a week. ? 0.6 gram. given each dose.

Date

28.2.44. Admitted to hospital. Strong, healthy young man with pronounced rash on face, and early 
rash on trunk and limbs, 3 to 4 days history. Generalized erythema, face trunk and limbs. Scalp: Well marked pityriasis capitis.

Face, neck and ears: Dry. Scales tending to accumulate, particularly on forehead. Slight serous discharge behind ears.

Limbs: Extensor surfaces, forearms and thighs show isolated, dry, scaly areas. Early pitting edema of ankles. W.R.: Negative. Conjunctivae: Clear. Tongue: Clean and moist.

Viscera: Nil abnormal.

2.3.44. Generalized edema, most marked on face and ankles. Purulent conjunctivitis. Face: Much more red. Free serous discharge, particularly from forehead. $2 \mathrm{ml}$. BAL.

3.3.44. $2 \mathrm{ml}$. BAL b.d. Skin seems drier but still markedly edematous. General condition very good.

4.3.44. $2 \mathrm{ml}$. BAL b.d. Less edema. Skin much drier. Thick scaling on scalp and face.

5.3.44. $2 \mathrm{ml}$. BAL b.d. Remittent temperature.

6.3.44. Much less edema. Increased pyrexia. General condition still very good.

8.3.44. The gross swelling is subsiding. Skin remains very dry. Cough and sore throat. Tongue: Dry. Chest: Nil. White count: 10000. Differential: Nil abnormal.

9.3.44. Forehead and periorbital region weeping freely. Temp. rising.

10.3.44. Sore throat worse. Tongue very dry, although taking fluids well and in excellent spirits. Face: Weeping profusely and edema much more pronounced. Can hardly open eyes. Still purulent conjunctivitis, despite frequent irrigations.

Began local treatment for skin: 1 per cent ichthyol and calamine lotion. $2 \mathrm{ml}$. BAL.

11.3.44. $2 \mathrm{ml}$. BAL b.d. Increasing erythema of chest.

12.3.44. $2 \mathrm{ml}$. BAL b.d.

13.3.44. $2 \mathrm{ml}$. BAL. Throat very sore and dry. Tongue clear and dry.

14.3.44. Still pyrexial. Throat now giving most trouble. Skin much improved.

15.3.44. Skin dry and peeling. Some deterioration in general condition. Less erythema. Now has an aphonia. Throat swab: Direct smear showed a heavy mixed bacterial flora. No excess of streptococci. No K.L.B. No Vincent's. Culture: Mixed bacterial growth with diphtheroid bacillus predominating.

16.3.44. Marked decline in general condition. Calciostab. $6 \mathrm{ml}$. daily (for skin condition).

17.3.44 Very ill. Cannot speak. Throat dry, coated and brown. Commencing white sloughs on posterior pharyngeal wall.

White count : 4000 .

Small monos: 208052 per cent

Large monos: 1604 per cent

Polymorphs: 176044 per cent

Eosins
Sodium pentose nucleotide $30 \mathrm{ml}$. per diem. Morphia gr. 1/4 nocte.

18.3.44. Great extension of white sloughs, covering tongue, palate and pharynx. Facies Hippocratica.

19.3.44. Patient died.

Case No. 16. Malc, aged 23.U.S.M.C.

Lt. Colonel D. M. Pillsbury.

Typical diffuse severe arsphenamine dermatitis, developing after 15th injection of Mapharsen in routine treatment given twice weekly.

Date

24.2.44. Admitted to hospital with bilateral pneumonia.

6.3.44. Treatment until this date consisted of 720,000 units of penicillin, $500 \mathrm{ml}$. whole blood, and 1500 ml. plasma. By 6th March patient had improved greatly in regard to the pneumonic infection. The dermatitis had shown no improvement. 2 ml. BAL given. Diffuse weeping, severe dermatitis.

7.3.44. $2 \mathrm{ml}$. BAL b.d. Skin paler, almost complete cessation of weeping. Also received $500 \mathrm{ml}$. plasma for hypoproteinaemia.

8.3.44. $2 \mathrm{ml}$. BAL b.d. Continued paling of skin. complete cessation of weeping.

9.3.44. $2 \mathrm{ml}$. BAL b.d. Skin practically normal in appearance. BAL discontinued. The patient later developed some pyoderma which was controlled by oral sulphadiazine therapy and potassium permang. baths.

Case No. 17. Male.

U.S.M.C.

Lt. Col. D. M. Pillsbury.

Patient received full course of 20 injections of Mapharsen and 8 injections bismuth over a 20 day period for secondary syphilis.

Two days following last injection patient developed generalized erythema of the skin, with considerable itching.

The dermatitis rapidly become more severe, and some exfoliation was noted.

Injections of BAL were given, 4 ampoules of $100 \mathrm{mgm}$. during the first 24 hours, and 2 ampoules during the second 24 hours.

Marked improvement was noted during the second day of BAL treatment, consisting of subsidence of itching and blanching of the skin.

No further BAL was given and improvement continued, the skin being practically normal on the fifth day after onset of dermatitis.

Case No. 18.

Yeovil V. D. Clinic. Dr. D. V. Hague.

Primary syphilis and acute gonorrhea diagnosed on serological findings.

Date

10.1.44. W.R. ++. Kahn ++.

17.1.44. to 16.3.44. Stabilarsan 4.8 grams. Bismuth 2.1 grams. Also sulphathiozole. 
23.3.44. Tonsillitis and slight seborrhoeic rash. Bismuth 0.3 gram.

20.4.44. Arsenical dermatitis. Bismuth. 0.2 gram. Thiostab. 0.45 gram.

27.4.44. W.R. and Kahn negative. Considerable exudative dermatitis. Thiostab. 0.45 gram.

29.4.44. Admitted to hospital. Vesicular rash on arms and legs, with edema and slight crusting of exudate. Slight right conjunctivitis. Tongue normal. Slight ulcerative stomatitis. $2 \mathrm{ml}$. $\mathrm{BAL}$ given.

30.4.44 to 3.5.44. BAL $2 \mathrm{ml}$. b.d. No local or general reaction.

4.5.44. Much worse. Generalized rash. Edema of face, both limbs and trunk with crusting exudate. Pyrexia.

5.5.44. Slight improvement.

11.5.44. Much worse. Swinging pyrexia, albuminuria, marked edema of face, limbs and trunk with crusted exudate.

14.5.44. On examination (D.I.W.) : Well built brunette whose general condition seems very good.

Hair: Matted with crusted exudate.

Forehead: Closely packed pustules, some broken down and oozing pus.

Face: Covered with dry scales peeling off in flakes the size of a farthing.
Eyes: Purulent conjunctivitis. Slight edema of conjunctivae. Edema of lids. No icterus of conjunctivae.

Neck: Fierce erythema with some scaling of a branny type.

Arms: Bright red; fine scaling; a few areas of active vesicle formation. Fissuring in flexures of wrist, elbow and in axillary folds.

Hands: Normal.

Trunk: Fissuring under breasts and in groins. General erythema; fine scaling; small irregular papules all over trunk.

Legs: Acute vesicular eruption. Shiny, edematous, fiery red skin. No exudation. Edema of ankles and feet.

Feet: Skin normal.

Urine normal; no adventitious sound in chest.

15.5.44 to 16.5.44. BAL $2 \mathrm{ml}$. b.d.

17.5.44. Patient very ill, with marked pyrexia and albuminuria. BAL $2 \mathrm{ml}$.

20.5.44. Sulphathiazole given.

13.6.44. Patient has continued to improve since 21.5.44, but with occasional relapses. Skin slowly returning to normal. Dry and scaly all over. Now fairly fit.

(Seen by D. I. W. on 14.5.44.)

Case No. 19

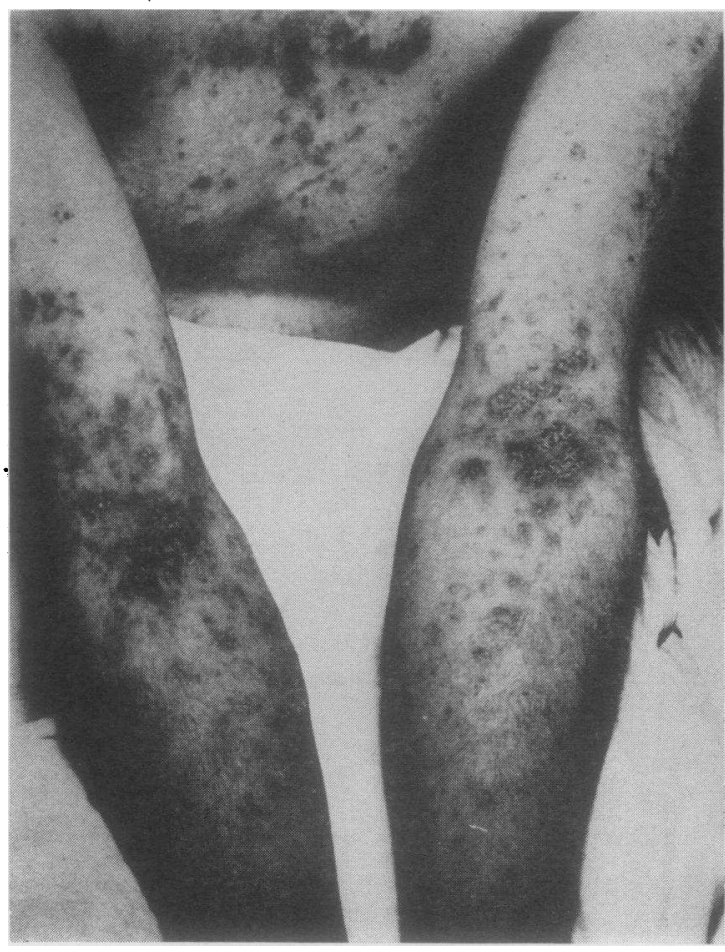

8th May 1943.

Taken immediately before first application of OX.217 ointment.



20th May 1943.

Taken 12 days after first application of OX.217 ointment. 
Case No. 19. Male.

Royal Victoria Hospital, Netley,

Date

Major D. I. Williams, R.A.M.C.

28.12.42. Gingivitis. W.R. alleged positive previously. W.R. repeated 30.12.42: Positive.

Kahn 30.12.42: Negative.

Diagnosed as latent syphilis.

1.1.43 to 27.1.43. Received Mapharside, 0.28 gram.

3.2.43 to 24.3.43. Received N.A.B. 3.6 grams.

24.4.43. Attended hospital, W.R. negative. Kahn negative.

Acute eczematization of both elbow flexures, with scattered papules on arms and chest (none on legs or face). Scabies 3 months earlier treated with sulphur and benzyl benzoate. Present skin condition diagnosed as an early arsenical dermatitis.

8.5.43. Well marked dermatitis of face, neck, ears, arms and chest.

Admitted to hospital. Colour photograph taken. BAL (10 per cent) ointment then applied to right side of face, neck and chest and to right elbow flexure; vaseline applied over corresponding areas on the left side.

9.5.43. No apparent change in the condition.

10.5.43. Applications of BAL ointment to right side and vaseline to left side as on 8.5.43.

11.5.43. General improvement in the condition of the skin, but no difference detected between right and left sides.

13.5.43. Still improving.

14.5.43. Right side somewhat better than left.

17.5.43. Some irritation present over the left antecubital fossa. BAL ointment applied to the affected part, vaseline to corresponding area on right arm.

20.5.43. Continued general improvement. Papular element markedly receding.

24.5.43. Skin healed. Some xeroderma still present, probably constitutional.

1.6.43. Skin still healthy. Discharged to light duty.

7.6.43. Re-admitted to hospital, complaining of recurrence of skin trouble 3 days after discharge. On examination, some activity seen over chest, both antecubital fossae and forearms; condition only slight with no papular element. On questioning, patient admitted that arms had been exposed to sunlight while on duty after discharge.

9.6.43. BAL applied to both sides.

10.6.43. Further application of BAL. Much improved. 14.6.43. Discharged, well.

5.7.43. Seen at hospital, when attending for blood test. Complained of another slight recurrence 3 days after discharge (i.e. on 17.6.43) which improved with calamine lotion and vaseline; on examination very mild eczematization of both elbow flexures. Photographs appended.
Case No. 20. Male, aged 39. Harrow Road Hospital, London, W.9.

Major E. J. Mannix, R.A.M.C.

History: Primary syphilis, March 1943.

Dark ground + . No record of original W.R.

Date

23 to 25.3.43. Mapharside 0.08 gram. Bis. 0.4 gram.

2.4.43 to 18.5.43. N.A.B. 3.0 grams. Bis. 1.4 grams.

18.5.43. Kahn negative.

10.6.43. Bis. 0.2 gram.

17.6.43. N.A.B. 0.6 gram. Bis. 0.2 gram.

24.6.43. Pityriasiform rash on chest, abdomen, thighs and forearms, observed in patient some 4 days previously.

24.6.43 to 29.6.43. Bis. 2 grams.

26.6.43. Admitted to hospital.

Treatment and progress.

29.6.43. BAL ointment applied all over affected area. This caused great stinging and it was washed off at once; there was a brisk urticarial reaction.

29.6.43 to 12.7.43. Received 28 applications of BAL applied twice daily over an area of 3 sq. in. of normal skin on the arms. The skin showed pigmentation within a few days, which had almost subsided within a week, and was gone in a fortnight.

No other local treatment given.

4.7.43. Developed jaundice. Treated by diet and mist. alba.

Case No. 21. Male, aged 26. Harrow Road Hospital, London, W.9.

Major E. J. Mannix, R.A.M.C.

History: Primary syphilis 17.4.43. W.R. ++. Dark ground + .

Date

17.4.44 to 15.5.43. N.A.B. 3.15 grams. Bis. 1.4 grams.

5.6.43. Admitted with erythema of both forearms, thighs and calves. During next week feet and face became very edematous. Eruption on feet became vesicular and erythematous, and a similar but milder condition appeared on the face. Condition of arms meanwhile appeared to subside.

5.6.43 to 28.7.43. Bis. 2.6 grams.

Treatment and progress.

During the first week he was treated with calamine, but when weeping occurred was put on to pot. permang. baths.

29.6.43. BAL ointment applied to the normal skin of his chest over an area of 9 inches square. This caused erythema and some burning. Subsequently, therefore, he received inunctions into normal skin on the arms over areas 3 inches square. In all, he received 14 applications, twice daily between 29.6 .43 to 5.7 .43 . 
5.7.43. Developed a papular eruption at the site of inunction. His feet were relapsing. Inunctions were stopped.

30.7.43. He is now well.

Inunction had no beneficial effect.

Case No. 22. Male.

Surgeon Comm. E. G. Thomas, R.N.V.R.

Date

16.5.43 to 19.7.43. Treatment for sero-positive syphilis. N.A.B. 4.05 grams. Bicreol. $12 \mathrm{ml}$.

27.7.43. Admitted to hospital on account of arsenical dermatitis. Condition was generalized and severe; the face was edematous, the trunk and limbs were a bright red colour, and on the skin were numerous vesicles and pustules.

31.7.43 to 2.8.43. 5 per cent BAL ointment rubbed in daily, over different areas of only mildly affected skin on the trunk.
Little change noticed until 7.8.43.

10.8.43. General improvement remarkable. Edema has disappeared, the skin of the trunk is rapidly approaching normal, and the limbs are dry and show some scaling.

26.9.43. Dermatitis recurred on forearms, and rapidly became generalized, exfoliating as in the previous attack.

2.10.43 to 4.10.43. Treated with BAL ointment.

Condition improved gradually.

(Seen by R. H. S. T. on 31.7.43.)

Photographs appended.

Case No. 23. Male. Harrow Road Hospital, London, W.9.

History.

Major E. J. Mannix, R.A.M.C.

Date

6.7.43. Primary syphilis. W.R. ++ .

Case No. 22

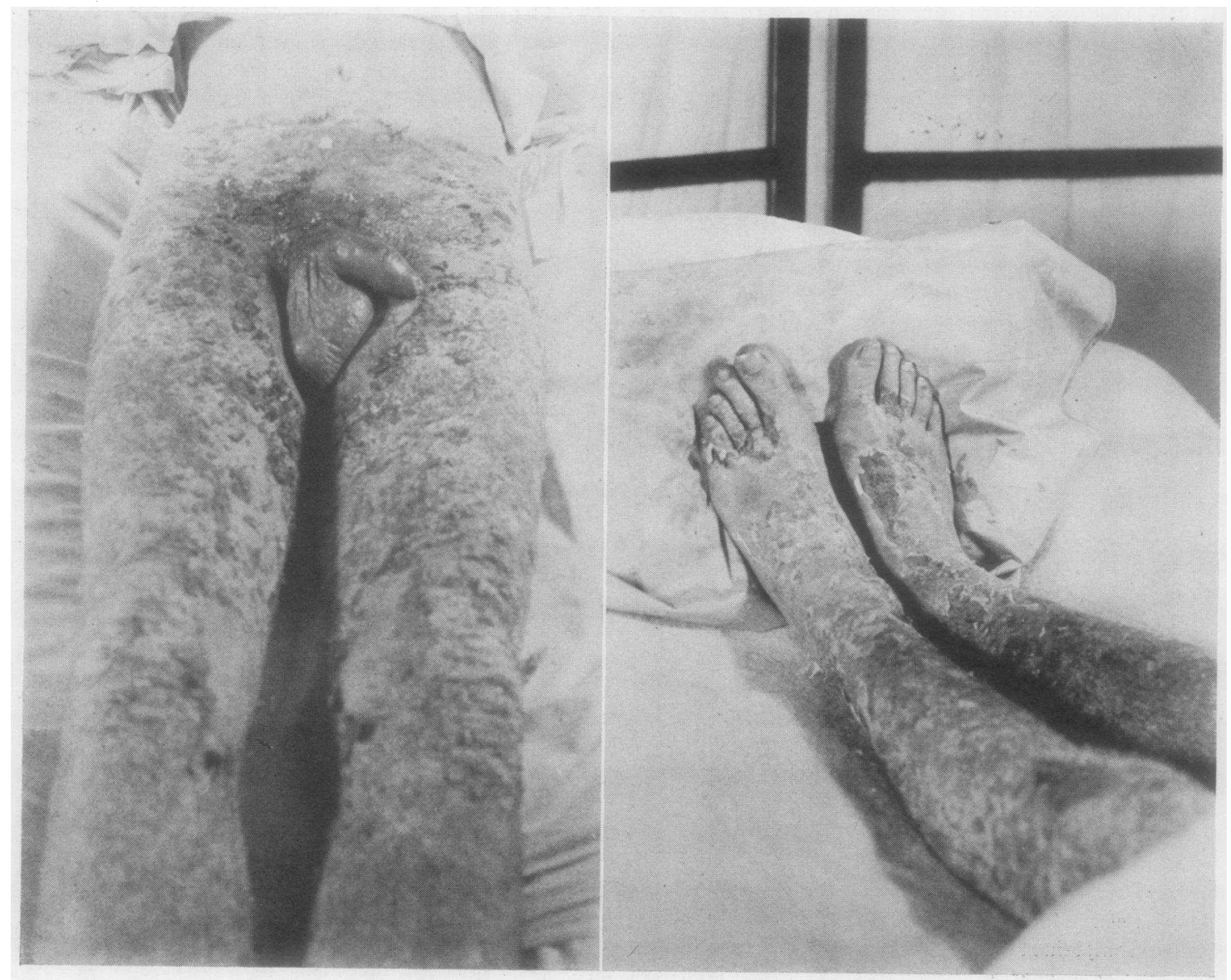

2.8.43.

2.8.43.






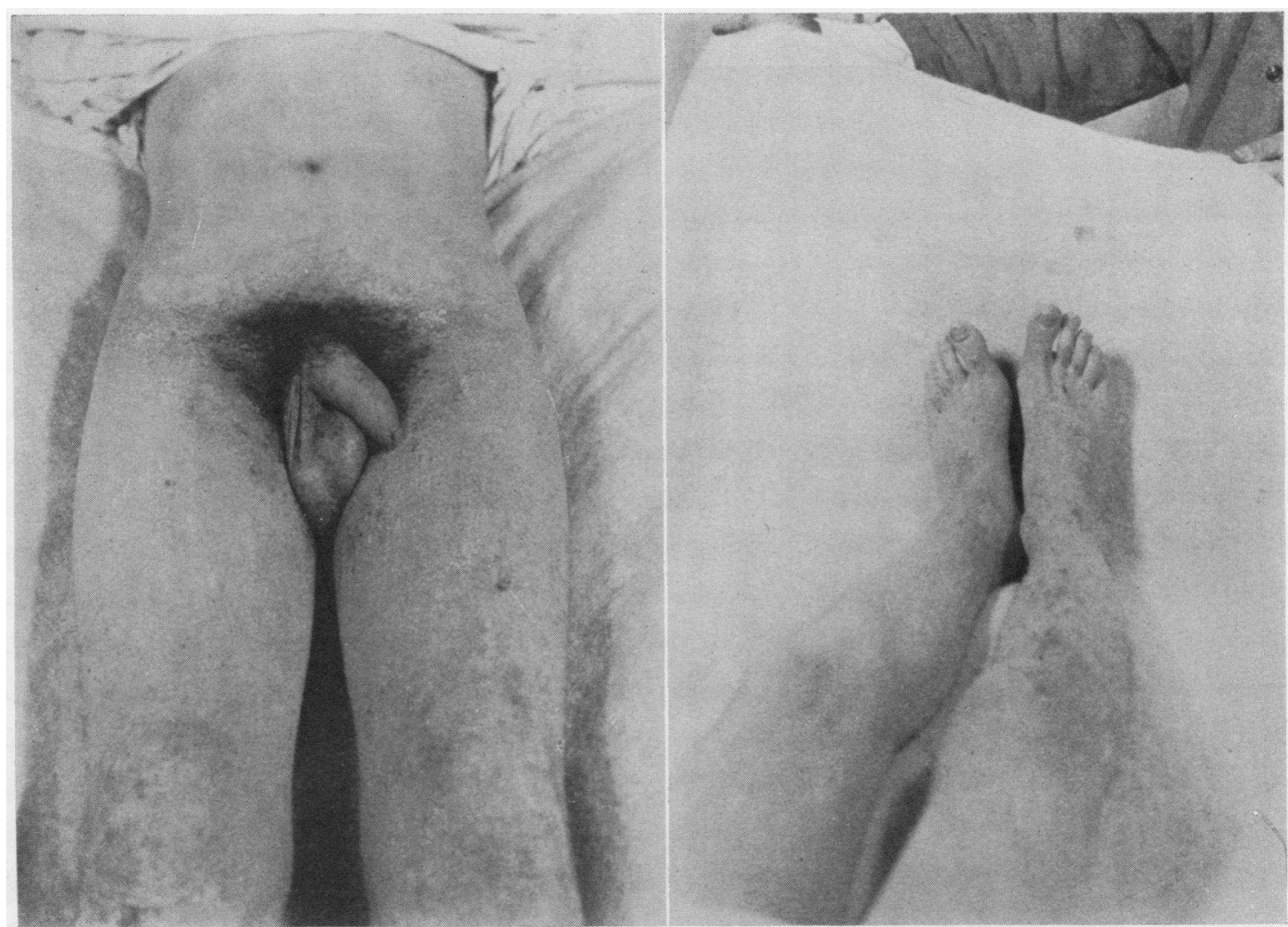

12.8.43.

12.8.43.

Twelve days after the first inunction of OX.217 ointment.

6.7.43 to 25.8.43. 8 injections neoarsphenamine with $\mathrm{Bi}$.

1.9.43. Erythematous rash on external surface of forearm. Treated with calamine cream.

5.9.43. Admitted to hospital with arsenical dermatitis. There was a papular rash on both forearms and arms, and on both knees, where there was some weeping. Rt. knee worse than left.

Chest, abdomen and buttocks were clear.

Backs of calves and ankles showed a moist dermatitis.

Treatment and progress.

7.9.43 to 13.9.43. Twelve inunctions of BAL ointment. The ointment was rubbed thoroughly into an area of healthy skin (about 2 in. in diameter) in the shoulder area, twice daily. Patient complained of some stinging a few minutes after each inunction. Skin of knees and ankles breaking down. From 10.9.43 to 13.9 .43 these areas were covered with saline dressings.

13.9.43. Patient obviously worse, with weeping areas on right knee and dorsum of left ankle and scattered patches on arms and legs.

BAL treatment was stopped, and he was put on pot. permang. baths and lin. cal. to the quies- cent patches. He showed improvement within 24 hours.

20.9.43. Skin peeling from palms of hands and soles of feet, but apart from slight erythema of the knees there were no signs of activity.

2.10.43. Discharged. No beneficial effect of the $B \Lambda L$ inunctions observed.

Case No. 24. Female, aged 23.

County Hospital, York.

Date

Dr. S. G. Platts.

15.10.43. Peeling of skin following sixth injection of 0.45 gram stabilarsan. The dermatitis spread rapidly, involving most of the body, and being especially bad on face and legs.

22.10.43. Admitted to hospital.

29.10.43 to 8.11.43. BAL ointment applied over small areas of healthy skin on arms, feet, hands, breasts and loins.

31.10.43. Improvement in generalized rash. Patient can now open the eyes.

10.11.43. Temp. $103^{\circ}$. Some secondary infection on cheeks and in the bends of the elbows. Ung. sulphathiazole applied to the affected areas. Desquamation has now ceased. 
CAse No. 24

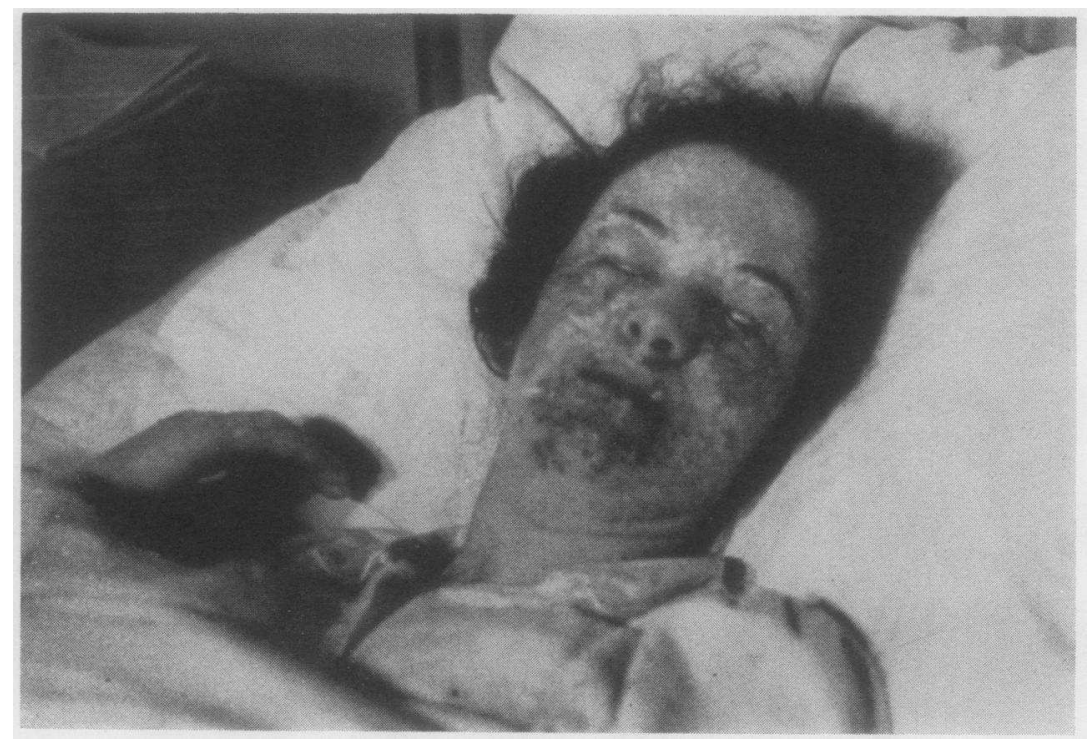

\subsubsection{3.}

Four days after the first inunction of OX.217 ointment.

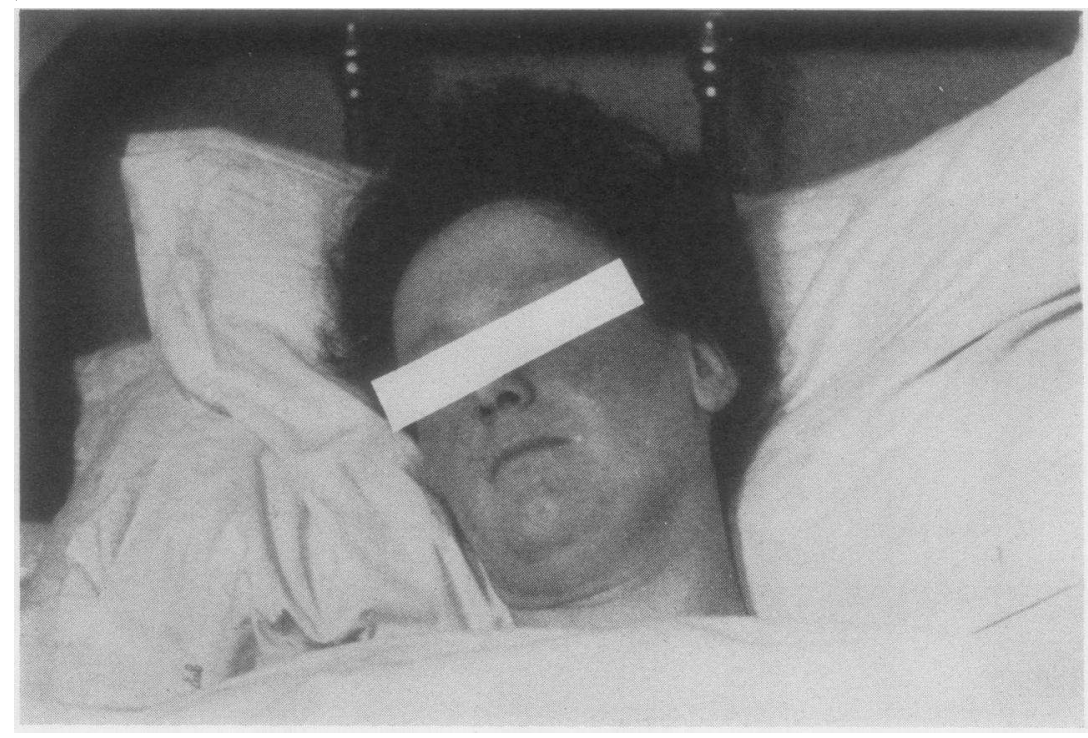

25.11.43.

Twenty-seven days after the first inunction of OX.217 ointment.

15.11.43. Temperature settled.

26.11.43. Discharged from hospital.

Patient's mother has also had an attack of arsenical dermatitis. It was less severe than the present case, but took at least 3 months to clear, though there was no delaying secondary infection.

Photographs appended.
Case No. 25. Male, ayed 44. Belmont Road Hospital, Liverpool.

Dr. C. McGibbon.

Papular syphilide. W.R. negative.

Date

7.10.43. Stabilarsan 0.45 gram and bismuth. 
7.10.43 to 5.11.43. Marpharside 0.06 gram given 3 times each week, until 14 injections had been given.

5.11.43. Exfoliative dermatitis. Treated as outpatient for 9 days. $\mathrm{Ca}$ gluconate given i.v. daily. Admitted to hospital.

Condition of admission: Generalized erythema, with fine, dry, branny scales over the whole body, more marked on abdomen, face and scalp. Treated with BAL ointment, this being applied to the abdomen and upper arms on 3 consecutive days. Within 1 to 2 days of each application there was a noticeable clearing of the scales, and to a lesser extent of the erythema, for a radius of about 3 to 4 in. from the site of application.

Seven days after the first inunction, as the face was still scaly, the ointment was applied to the cheek and forehead on 1 side of the face only, once daily for 3 days; this time there was a marked contrast between the treated and untreated halves of the face, the former being almost free from scales, while the latter was still thickly scaly; the abdomen showed a slight return of the scaling, but not nearly so marked as on admission.

Complete recovery 21 days after the first inunction; no other local treatment given. General condition excellent throughout; no serous discharge from the skin at any stage.

Case No. 26. Male, aged 46. Belmont Road Hospital, Liverpool.

Date Dr. C. McGibbon.

19.11.43. Diagnosed as secondary syphilis.

Generalized macular roseolar rash present for 7 days.

W.R. strongly positive.

No history of previous skin trouble.

N.A.B. 0.45 gram, alternating with 0.3 gram twice daily.

Two days after the 11th injection (i.e. after 4.05 grams of N.A.B.) he developed a generalized erythema. This was not diffuse, but appeared to follow the pattern of the subcutaneous blood vessels. The rash faded on pressure. No papules, vesicles or scaling.

BAL ointment applied to abdomen once daily for 4 days. By the end of the treatment the erythema was only slight.

Six days later, i.e. 10 days after the commencement of treatment, the skin was normal.

Case No. 27. Male.

Royal Infirmary, Liverpool, 3.

Dr. Ross.

Sero-positive primary syphilis.

Date

25.9.42 to 2.11.42. Mapharside 0.6 gram. Bismuth 1.2 grams.
4.11.42. Blood W.R. negative.

16.2.43. Blood W.R. negative.

22.2.43 to 1.3.43. Mapharside 0.14 gram. Bismuth 0.3 gram.

5.3.43. Became jaundiced. Icteric index 30 .

13.8.43. Icteric index 7.

18.8.43 to 2.11.43. Mapharside 0.36 gram. Bismuth 1.8 grams.

15.11.43. Developed a maculo-erythematous arsenical dermatitis involving trunk and limbs.

Treatment with ung. sulph. and daily injections of calcium thio-sulphate and liver extract resulted in no improvement.

24.11.43 to 25.11.43. BAL ointment applied twice daily.

1.12.43. Dermatitis has all but gone, though irritation is still bad at night. Calamine lotion prescribed.

Case No. 28. Male.

Health Department, Bridgewater. Dr. G. H. Pringle.

History. Primary syphilis in young adult male.

Date

15.9.43 to 3.11.43. Stabilarsan 3.6 grams. Bis. 1.6 grams.

10.11.43. Dermatitis. Injection thiostab. given. Dermatitis gradually became worse. Sodium thiosulphate injections had no effect.

1.12.43. Severe generalized exfoliative dermatitis. Face swollen, with blistering on the face and in the flexures. Hematuria present. The skin was pigmented and the patient complained of dryness of the mouth. No other constitutional symptoms.

4.12.43. Admitted to hospital.

4.12.43 to 7.12.43. $2 \mathrm{ml}$. BAL b.d. intramuscularly into the buttocks.

14.12.43 Two abscesses developed at injection sites.

23.12.43. Abscesses opened and drained under general anesthetic.

18.1.44. Marked steady improvement in the patient's general and local condition since 23.12.43.

The only local treatment was calamine lotion and olive oil, with the exception of 1 bath in 1 in 8000 pot. permang.

The condition is now almost clear.

Case No. 29. Male, aged 51.

Health Department, Nottingham.

Dr. R. Marinkovitch.

Plate-layer by occupation. Has never suffered from eczema or asthma. No history of asthma in the family.

\section{Date}

5.11.43. Attended for treatment of gummatous ulceration of R. elbow. W.R. ++.

15.11.43 to 21.1.44. Neoarsphenamine 4.35 grams. Bismuth oxychloride 2 grams.

W.R. strongly positive after completion of this course of therapy. 
12.2.44 to 25.3.44. N.A.B. 3.15 grams. Chlorostab. 1.4 grams.

1.4.44. Developed erythematous, itchy eruption on the legs (below the knees), and on forearms and face.

Calamine lotion applied.

8.4.44. Generalized erythema. Oozing and crusting of the skin on the neck, antecubital fossae, forearms, axillae, scrotum, lumbar region and legs below the knees.

15.4.44. Ears swollen, red and oozing. Scalp scaly. Edema and erythema of the face. Neck, axillae, lumbar region and scrotum exfoliating and crusting; neck very irritable. Forearms and legs angry-looking. Secondary infection in the lumbar region. Mucous membranes of the mouth and eyes grossly affected. Viscera, nil abnormal. Urine, no albumin.
19.4.44. BAL injections commenced. $2 \mathrm{ml}$. b.d. for 4 days.

20.4.44. Patient complained of generalized irritation. Mild pyrexia, $100.8^{\circ}$. No change in the skin condition.

21.4.44. Marked change noticed. Erythema, swelling and oozing disappeared. Desquamation and exfoliation increased all over body.

22.4.44. Patient comfortable. Skin desquamating and exfoliating in large flakes. Edema of the face and legs gone.

29.4.44. Relapsed. Erythema and intense irritation on the legs, back and neck. Local treatment commenced.

5.5.44. Erythema gone. Lichenification and exioliation on the posterior aspect of neck, and on the antecubital fossae and legs. Exfoliating on forearms, legs and lumbar region.

TABLE VI

Data on arsenical excretion

\begin{tabular}{|c|c|c|c|c|c|c|}
\hline Case & Before injectio & of BAL & During inject & $n$ of $\mathrm{BAL}$ & After injecti & of BAL \\
\hline \multirow[t]{2}{*}{1} & \multirow[t]{2}{*}{$\begin{array}{l}\text { Oct. } 31 \text { to Nov. } 1 \\
\begin{aligned} \text { Nov. } 1 \text { to } 2 \\
2 \text { to } 3\end{aligned}\end{array}$} & \multirow[t]{2}{*}{\begin{tabular}{|c|} 
mgm. As per diem \\
0.351 \\
0.249 \\
0.150
\end{tabular}} & $\begin{array}{r}\text { Nov. } 3 \text { to } 4 \\
4 \text { to } 5 \\
5 \text { to } 6\end{array}$ & \begin{tabular}{|c|} 
mgm. As per diem \\
0.196 \\
0.139 \\
0.221 \\
\end{tabular} & \multirow[t]{2}{*}{ 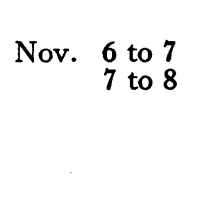 } & \multirow[t]{2}{*}{$\begin{array}{c}\text { mgm. As per diem } \\
0.221 \\
0.092\end{array}$} \\
\hline & & & $\begin{array}{l}8 \text { to } 9 \\
9 \text { to } 10 \\
\end{array}$ & $\begin{array}{l}0.131 \\
0.200 \\
\end{array}$ & & \\
\hline 2 & $\begin{array}{r}\text { Nov. } 10 \text { to } 11 \\
11 \text { to } 12\end{array}$ & $\begin{array}{l}0.168 \\
0.143\end{array}$ & $\begin{array}{r}\text { Nov. } 12 \text { to } 13 \\
13 \text { to } 14 \\
14 \text { to } 15\end{array}$ & $\begin{array}{l}0.193 \\
0.180 \\
0.208\end{array}$ & . & \\
\hline 4 & Dec. 6 & $\begin{array}{l}0.538 \\
0.787\end{array}$ & 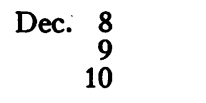 & $\begin{array}{l}0.530 \\
0.775 \\
0.708\end{array}$ & Dec. $\begin{array}{r}11 \\
12\end{array}$ & $\begin{array}{l}0.583 \\
0.456\end{array}$ \\
\hline 5 & $\begin{array}{r}\text { Dec. } 24 \\
25 \\
26\end{array}$ & $\begin{array}{l}0.485 \\
0.275 \\
0.236\end{array}$ & $\begin{array}{r}\text { Dec. } 27 \\
28 \\
29\end{array}$ & $\begin{array}{l}0.297 \\
0.166 \\
0.186\end{array}$ & 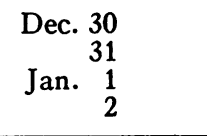 & $\begin{array}{l}0.202 \\
0.160 \\
0.245 \\
0.119\end{array}$ \\
\hline 6 & $\begin{array}{r}\text { Dec. } 26 \text { to } 27 \\
27 \text { to } 28\end{array}$ & $\begin{array}{l}0.362 \\
0.298\end{array}$ & $\begin{array}{r}\text { Dec. } 28 \text { to } 29 \\
29 \text { to } 30 \\
30 \text { to } 31\end{array}$ & $\begin{array}{l}0.347 \\
0.379 \\
0.246\end{array}$ & & \\
\hline 7 & $\begin{array}{r}\text { Jan. } 4 \text { to } 5 \\
5 \text { to } 6 \\
6 \text { to } 7 \\
7 \text { to } 8\end{array}$ & $\begin{array}{l}0.493 \\
0.529 \\
0.129 \\
0.350\end{array}$ & $\begin{array}{r}\text { Jan. } 8 \text { to } 9 \\
9 \text { to } 10 \\
10 \text { to } 11\end{array}$ & $\begin{array}{l}0.437 \\
0.291 \\
0.435\end{array}$ & $\begin{array}{r}\text { Jan. } 11 \text { to } 12 \\
12 \text { to } 13 \\
13 \text { to } 14\end{array}$ & $\begin{array}{l}0.286 \\
0.251 \\
0.232\end{array}$ \\
\hline 8 & $\begin{array}{r}\text { Jan. } 22 \\
23 \\
24\end{array}$ & $\begin{array}{l}0.607 \\
0.339\end{array}$ & $\begin{array}{r}\text { Jan. } 25 \\
26 \\
27 \\
28\end{array}$ & $\begin{array}{l}0.396 \\
0.354\end{array}$ & $\begin{array}{r}\text { Jan. } 29 \\
30 \\
\text { Feb. } 10\end{array}$ & $\begin{array}{l}0.233 \\
0.274 \\
0.094\end{array}$ \\
\hline \multirow[t]{2}{*}{9} & \multirow[t]{2}{*}{$\begin{array}{l}\text { Feb. } 3 \text { to } 4 \\
4 \text { to } 5\end{array}$} & \multirow[t]{2}{*}{$\begin{array}{l}1.190 \\
1.470\end{array}$} & 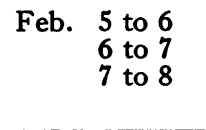 & $\begin{array}{l}0.848 \\
0.750 \\
0.945\end{array}$ & $\begin{array}{r}\text { Feb. } 8 \text { to } 9 \\
9 \text { to } 10 \\
10 \text { to } 11 \\
11 \text { to } 12\end{array}$ & $\begin{array}{l}0.650 \\
0.527 \\
0.576 \\
0.340\end{array}$ \\
\hline & & & $\begin{array}{r}\text { Feb. } 12 \text { to } 13 \\
13 \text { to } 14 \\
14 \text { to } 15\end{array}$ & $\begin{array}{l}0.450 \\
0.390 \\
0.520\end{array}$ & $\begin{array}{r}\text { Feb. } 15 \text { to } 16 \\
16 \text { to } 17 \\
17 \text { to } 18 \\
18 \text { to } 19\end{array}$ & $\begin{array}{l}0.520 \\
0.305 \\
0.555 \\
0.250\end{array}$ \\
\hline
\end{tabular}


TABLE vi-Continued

\begin{tabular}{|c|c|c|c|c|c|c|}
\hline Case & \multicolumn{2}{|c|}{ Before injection of BAL } & \multicolumn{2}{|c|}{ During injection of BAL } & \multicolumn{2}{|c|}{ After injection of BAL } \\
\hline 10 & Feb. 13 & \begin{tabular}{|c|} 
mgm. As per diem \\
0.398
\end{tabular} & 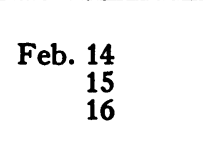 & \begin{tabular}{|c|} 
mgm. As per diem \\
0.588 \\
0.958 \\
1.120
\end{tabular} & 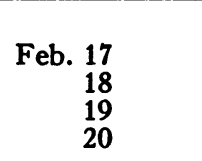 & \begin{tabular}{|c|} 
mgm. As per diem \\
0.777 \\
1.310 \\
0.690 \\
1.030
\end{tabular} \\
\hline 11 & Feb. 14 & $\begin{array}{l}1.93 \\
0.59\end{array}$ & $\begin{array}{r}\text { Feb. } 16 \\
17 \\
18 \\
19\end{array}$ & $\begin{array}{l}0.78 \\
0.87 \\
0.89 \\
0.75\end{array}$ & $\begin{array}{r}\text { Feb. } 20 \\
21 \\
22 \\
23\end{array}$ & $\begin{array}{l}0.72 \\
0.82 \\
0.65 \\
0.35\end{array}$ \\
\hline 12 & $\begin{array}{r}\text { Mar. } 14 \text { to } 15 \\
15 \text { to } 16 \\
16 \text { to } 17 \\
17 \text { to } 18\end{array}$ & $\begin{array}{l}0.24 \\
0.45 \\
0.26 \\
0.93\end{array}$ & $\begin{array}{r}\text { Mar. } 18 \text { to } 19 \\
19 \text { to } 20 \\
20 \text { to } 21 \\
21 \text { to } 22 \\
22 \text { to } 23 \\
23 \text { to } 24\end{array}$ & $\begin{array}{l}0.41 \\
0.50 \\
0.31 \\
0.38 \\
0.37 \\
0.33\end{array}$ & $\begin{array}{r}\text { Mar. } 24 \text { to } 25 \\
25 \text { to } 26\end{array}$ & $\begin{array}{l}0.30 \\
0.39\end{array}$ \\
\hline 13 & $\begin{array}{c}\text { Feb. } 26 \text { to } 29 \\
3 \text { days }\end{array}$ & 1.050 & $\begin{array}{l}\text { Feb. } 29 \\
\text { Mar. } 3\end{array}$ & 0.744 & $\begin{array}{l}\text { Mar. } 3 \text { to } 4 \\
4 \text { to } 7\end{array}$ & $\begin{array}{l}0.180 \\
0.437\end{array}$ \\
\hline \multirow[t]{2}{*}{15} & \multirow[t]{2}{*}{$\begin{array}{r}\text { Mar. } 4 \text { to } 5 \\
5 \text { to } 6\end{array}$} & \multirow[t]{2}{*}{$\begin{array}{c}0.134 \\
100 \mathrm{ml} . \\
0.076 \\
100 \mathrm{ml} .\end{array}$} & $\begin{array}{r}\text { Mar. } 6 \text { to } 7 \\
7 \text { to } 8 \\
8 \text { to } 9\end{array}$ & $\begin{array}{l}1.16 \\
0.96 \\
0.67\end{array}$ & \multirow[t]{2}{*}{$\begin{array}{r}\text { Mar. } 9 \text { to } 10 \\
10 \text { to } 11 \\
11 \text { to } 12\end{array}$} & $\begin{array}{l}0.35 \\
0.57 \\
0.42\end{array}$ \\
\hline & & & $\begin{array}{l}12 \text { to } 13 \\
13 \text { to } 14\end{array}$ & $\begin{array}{l}0.16 \\
0.32\end{array}$ & & . \\
\hline 16 & $\begin{array}{l}\text { Feb. } 29 \\
\text { Mar. } 1\end{array}$ & $\begin{array}{l}2.56 \\
1.90\end{array}$ & $\begin{array}{r}\text { Mar. } 2 \\
3 \\
4 \\
5\end{array}$ & $\begin{array}{l}2.47 \\
1.97 \\
2.56 \\
0.96\end{array}$ & $\begin{array}{r}\text { Mar. } \begin{array}{r}6 \\
7 \\
8\end{array}\end{array}$ & $\begin{array}{l}1.17 \\
0.97 \\
1.04\end{array}$ \\
\hline
\end{tabular}

\begin{tabular}{|c|c|c|}
\hline & & As. $\underset{\text { gram. per }}{\text { Mram }}$ \\
\hline Case 2 & $\begin{array}{l}\text { Before Injection } \\
\text { During Injection }\end{array}$ & $\begin{array}{l}9.2 \\
8.2 \\
7.0\end{array}$ \\
\hline Case 7 & Before Injection & 8.0 \\
\hline Case 8 & Before Injection & 2.8 \\
\hline Case 10 & On day of first Injection & 6.3 \\
\hline Case 12 & Before Injection & 3.5 \\
\hline Case 16 & (not known) & 9.2 \\
\hline
\end{tabular}

Grateful acknowledgment is here made to all who have so willingly co-operated in this therapeutic trial. We are particularly indebted to Maj.-Gen. L. T. Poole, D.S.O., M.C., K.H.P., Brigadier T. E. Osmond, Brigadier R. M. B. McKenna, F.R.C.P., Lt.-Col. W. J. O'Donovan, O.B.E., Lt.-Col. A. J. King and Major E. J. Mannix, R.A.M.C., for their help, and to Col. L. W. Harrison, C.B., D.S.O., for his co-operation at the Ministry of Health. Thanks are also due to Messrs. Boots Pure Drug Co., Ltd., and Burroughs, Wellcome \& Co., for their assistance, and to Prof. A. D. Gardner for advice in the preparation of the ampoules, to Messrs. Parke, Davis \&
Co., for a gift of undiluted Mapharside, to the Medical Research Council for a grant towards their cost, to Dr. E. R. Holiday, the Metal Box Co., and the Photographic Department of the Experimental Station, Porton, (Ministry of Supply) for photographic assistance, and to Mrs. Fisher and Miss J. Allen for secretarial help.

We also wish to thank the clinicians mentioned in the report for permission to publish details of cases under their care.

12.5.44. Exfoliation continues.

19.5.44. Desquamation on back, neck, axillae, scrotum, legs and lumbar region. Reaching subacute stage.

Sedatives administered for irritation.

26.5.44. No change.

3.6.44. Irritation and oozing on chest and forearms, lichenification of neck. Soothing creams applied. Sedatives for irritation.

7.6.44. Patient feels comfortable. Skin still irritable. New area of erythema on the back of the chest, with some exfoliation. Slight desquamation.

\section{Case No. 30. Male. U.S.M.C.}

Lt. Col. D. M. Pillsbury.

After 6th injection of Mapharsen, developed chills, fever of $101^{\circ}$ and a pink, plaque-like type of eruption involving the upper half of the body. 
The eruption gradually became generalized.

20.3.44. Initial injections of $B A L$ given. After one injection almost immediate mottled blanching was noted, and his temp. dropped 4 degrees to $101^{\circ}$.

Two further injections were given during the next 24 hours, and complete blanching of the skin was noted.

\section{APPENDIX II}

\section{EXCRETION OF ARSENIC}

I. D. E. STOREY, G. A. LEVVY, AND AVERIL C. CHANCE

\section{(Departments of Medical Chemisry and Pharmacology, Edinburgh)}

\section{Introduction.}

Arsenic analyses upon specimens of urine and of skin exfoliations from several cases of arsenical dermatitis have been done.

\section{Analytical methods.}

All estimations were carried out by the method previously described (24), using the large scale procedure with $\mathrm{AsCl}_{3}$ distillation. This was necessary in the case of skin, in spite of the small weights of samples, because of the difficulty in completely digesting this tissue. Analyses were carried out in replicate wherever possible, and especially when unusual results were encountered.

\section{Urine.}

It has been shown experimentally that injection of BAL will increase the excretion of arsenic in the urine of an animal poisoned with a trivalent arsenical. It is natural, therefore, to think that this will happen in patients suffering from arsenical poisoning: Eagle (21) has claimed that injection of BAL in oil increases excretion in man. Sample from 24-hour specimens of urine from some of the cases which have been described above, were sent to Edinburgh for analysis. The results are indicated in Table VI. In some cases there is a slight indication of correlation between an injection and a rise in excretion; but this may not be significant, owing to the large fluctuations always present. The general conclusion is that BAL in the doses given had no effect on the urinary elimination of arsenic in these cases.

\section{SKIN EXFQLIATIONS}

Specimens of skin exfoliations have been collected in pill boxes and sent to Edinburgh for analysis; the values obtained varied from 3.0 to 9.0 $\mu g$. As per gram. Though these estimations do not permit of conclusions as to the progress of the cases, they are put on record as we can find accounts of no other similar estimations, and as they establish the presence of amounts of arsenic in the skin capable of causing damage to the cells.

Though we cannot find records of arsenic estimation in exfoliations, there are accounts in the literature of the arsenic content of hair. Reference to some of these has been recently made by Young and Smith (25), who have themselves analysed hair from cases of arsenical poisoning. The values obtained by them varied from $7.7 \mu \mathrm{g}$. to $3.2 \mu \mathrm{g}$. per gram hair (dry weight) ; the higher value was for the proximal portion of scalp hair following a period of fatal illness of only 30 hours. The values are of the same order as those found for the skin exfoliations. ${ }^{2}$

\section{BIBLIOGRAPHY}

1. Meyerhof, O., Symposium on Respiratory Enzymes. Univ. Wisconsin Press, 1942.

2. Peters, R. A., Biochemical lesion in vitamin $B_{1}$ deficiency. Lancet, 1936, 1, 1161.

3. Peters, R. A., Effect of dichlor-diethylsulphone on brain respiration. Nature, 1936, 138, 327.

4. Krebs, H. A., Untersuchungen über den Stoff wechsel der Aminosäuren im Tierkörper. Z. physiol. Chem., 1933, 217, 191.

5. Peters, R. A., 1937, Chem. Weekblad. 34 and unpublished observations.

6. Sinclair, H. M., and Thompson, R. H. S., 1940, Report to $M$. of S. by Peters No. 4.

7. Peters, R. A., Stocken, L. A., and Thompson, R. H. S., British Anti-Lewisite. Nature, 1945, 156, 616.

8. Stocken, L. A., and Thompson, R. H. S., 1940, Report to M. of S. by Peters No. 25.

9. Stocken, L. A., and Thompson, R. H. S., Report to M. of S. by Peters No. 33.

10. Stocken, L. A., Thompson, R. H. S., and Whittaker, V. P., 1944, Report to M. of S. by Peters No. 78.

11. Eagle, H., 1943, Personal communication. Eagle, H., Magnuson, H. J., and Fleischman, R., The systemic treatment of experimental arsenic poisoning (mapharsen, Lewisite, phenyl arsenoxide) with BAL. J. Clin. Invest., 1946, 25, 451.

12. Thompson, R. H. S., and Stocken, L. A., 1941, Report to $M$. of S. by Peters No. 48.

2 Thanks is expressed to G. W. Abbot for his valuable technical assistance. 
13. Chance, A. C., 1944, Report to M. of S. by Levvy.

14. Sulzberger, M. B., and Baer, R., 1943, Personal communication. Sulzberger, M. B., Baer, R. L., and Kanof, A., Skin sensitization to BAL. J. Clin. Invest., 1946, 25, 488.

15. Stocken, L. A., and Thompson, R. H: S., 1943, Report to M. of S. by Peters No. 64 .

16. Eagle, H., 1943, Personal communication. Eagle, H., and Magnuson, H. J., The systemic treatment of 227 cases of arsenic poisoning (encephalitis, dermatitis, blood dyscrasias, jaundice, fever) with 2,3dimercaptopropanol (BAL). Am. J. Syph., in press.

17. Peters, R. A., Stocken, L. A., and Thompson, R. H. S., 1944, Report to M. of S. by Peters No. 77.

18. Longcope, W. T., Wintrobe, M. M., and Luetscher, J. A., 1943, Personal communication. Longcope, W. T., Luetscher, J. A., Jr., Wintrobe, M. M., and Jager, V., The treatment of arsenical dermatitis with preparations of BAL. J. Clin. Invest., 1946, 25, 528.
19. Peters, R. A., Thompson, R. H. S., King, A. J., Williams, D. I., and Nicol, C. S., Quart. J. Med., 1944, 13, 35 .

20. Davies, A., J. Roy. Nav. Med. Serv., 1943, 29, 153.

21. Eagle, H., 1944, Personal communication. Wexler, J., Eagle, H., Tatum, H. J., Magnuson, H. J., and Watson, E. B., The effect of BAL on the excretion of arsenic in normal subjects and after minimal exposure to arsenical smoke. J. Clin. Invest., 1946, 25, 467.

22. Bang, I., Biochem. Z., 1925, 165, 375.

23. Webster, S. H., Lead and arsenic content of urines from 46 persons with no known exposure to lead or arsenic. Pub. Health Rep., 1941, 56, 1953.

24. Levvy, G. A., Iodometric 'microdetermination of arsenic in biological material. Biochem. J., 1943, 37, 598.

25. Young, E. G., and Smith, R. P., Arsenic content of hair and bone in acute and chronic arsenical poisoning. Brit. M. J., 1942, 1, 251.

(M. of S. = U. K. Ministry of Supply.) 